\title{
A Critical Review of Lipid-based Nanoparticles for Taxane Delivery
}

\author{
Lan Feng ${ }^{1}$ and Russell J. Mumper ${ }^{1,2, *}$ \\ ${ }^{1}$ Center for Nanotechnology in Drug Delivery, Division of Molecular Pharmaceutics, UNC \\ Eshelman School of Pharmacy, University of North Carolina at Chapel Hill, Chapel Hill, NC \\ 27599, USA \\ UNC Lineberger Comprehensive Cancer Center, University of North Carolina at Chapel Hill, NC, \\ USA
}

\begin{abstract}
Nano-based delivery systems have attracted a great deal of attention in the past two decades as a strategy to overcome the low therapeutic index of conventional anticancer drugs and delivery barriers in solid tumors. Myriads of preclinical studies have been focused on developing nanobased formulations to effectively deliver taxanes, one of the most important and most prescribed anticancer drug types in the clinic. Given the hydrophobic property of taxanes, lipid-based NPs, serve as a viable alternative delivery system. This critical review will provide an overview and perspective of the advancement of lipid-based nanoparticles for taxane delivery. Currently available formulations of taxanes and their drawbacks as well as criteria for idea taxane delivery system will be discussed.
\end{abstract}

\section{Keywords}

taxane; lipid-based; nanoparticles

\section{Overview}

\subsection{Introduction of taxanes}

In the 1960s, the first taxoid was discovered by the National Cancer Institute.[1] The taxane family includes paclitaxel, docetaxel and analogues with the taxane skeleton. The high lipophilicity and the high lattice energy of paclitaxel and docetaxel which reflect their bulky and fused ring structure with several lipophilic substituents, result in very limited aqueous solubility (Figure 1). The water solubility of paclitaxel has been reported as $0.35-0.7 \mu \mathrm{g} /$ $\mathrm{mL} .[2,3]$ Although both being extensive water-insoluble, the structural differences make docetaxel about 10-fold more soluble in water (3-25 $\mu \mathrm{g} / \mathrm{mL})$ than paclitaxel.[4-6] Paclitaxel

(c) 2012 Elsevier Ireland Ltd. All rights reserved.

*Corresponding author: Russell J. Mumper, Ph.D., Vice Dean and John A. McNeill Distinguished Professor, Center for Nanotechnology in Drug Delivery, Division of Molecular Pharmaceutics, UNC Eshelman School of Pharmacy, CB\# 7355, 100G Beard Hall, University of North Carolina at Chapel Hill, Chapel Hill, North Carolina 27599-7355, mumper@email.unc.edu, Phone: (919) 966-1271, Fax: (919) 966-6919.

\section{Conflict of Interest Statement}

None

Publisher's Disclaimer: This is a PDF file of an unedited manuscript that has been accepted for publication. As a service to our customers we are providing this early version of the manuscript. The manuscript will undergo copyediting, typesetting, and review of the resulting proof before it is published in its final citable form. Please note that during the production process errors may be discovered which could affect the content, and all legal disclaimers that apply to the journal pertain. 
and docetaxel share many common chemical and biological properties but also have significant differences as summarized in Table 1.

In 1979, Schiff et al. discovered the unique pharmacological mechanism of taxanes.[7] Taxanes inhibit cell growth by binding to microtubules, stabilizing them, and preventing their depolymerization.[8, 9] Since the binding affinity of docetaxel to microtubule is 1.9fold higher than that of paclitaxel, docetaxel is approximately twice as potent as paclitaxel. $[8,10,11]$ The higher in-vitro and in-vivo anticancer potency of docetaxel may not only be attributed to its higher affinity for microtubules, but also to its superior cellular accumulation. In support of this, an in-vitro study of the uptake and efflux of radiolabeled docetaxel and paclitaxel on P388 leukemia cells demonstrated that intracellular accumulation of docetaxel was 3-fold higher than that of paclitaxel with the same initial extracellular concentration.[12] Conversely, the efflux rate of docetaxel from P388 cells was 3 -fold lower than that of paclitaxel.

\subsection{Currently available marketed formulations}

$\mathrm{Taxol}^{\circledR}$, the first injectable dosage form of paclitaxel is supplied in 50\% CrEL (polyoxyethylated castor oil) and 50\% dehydrated ethanol.[13] Following intravenous (i.v.) administration of Taxol, paclitaxel is rapidly eliminated from circulation. The average distribution half-life of paclitaxel after the administration of Taxol is $0.34 \mathrm{hr}$ and the average elimination half-life is $5.8 \mathrm{hr} .[14,15]$ The pharmacokinetics of Taxol is nonlinear. It has been concluded that the nonlinear disposition of paclitaxel is due to the formulation vehicle CrEL. Two mechanisms have been proposed to explain the nonlinearity pharmacokinetics of Taxol: 1) alteration of hepatic transport function,[16] and 2) change of erythrocyte accumulation. $[17,18]$ The large quantity of CrEL in the formulation especially at high dose likely changes hepatic transporter activity, which in turn profoundly influences hepatic uptake and biliary excretion rates of paclitaxel or other co-administered compounds. Another more widely accepted mechanism is that paclitaxel is highly entrapped in CrEL micelles and the free drug fraction available for cellular partitioning is reduced, leading to alteration of paclitaxel accumulation in erythrocytes and thereby dose-dependent disposition. The nonlinear pharmacokinetics of Taxol may raise additional complexities when combination chemotherapy regimens are applied. The CrEL-related issue is not limited to pharmacokinetics of Taxol. CrEL-related side effects have been reported in clinical practice. It is generally believed that the hypersensitivity reactions are largely attributed to the CrEL vehicle.[19]

The only clinically approved alternative to Taxol is Abraxane ${ }^{\circledR}$. Abraxane is prepared by high-pressure homogenization of paclitaxel in the presence of human albumin, resulting in a nanoparticle colloidal suspension with a mean particle diameter of 130-150 nm.[20] Clinical studies have demonstrated that the albumin-bound form of paclitaxel (i.e., nab-paclitaxel) has many clinical advantages over traditional Taxol. First, nab-paclitaxel is CrEL-free. Second, due to higher achievable concentration from nab-paclitaxel formulation, the drug can be administered over a shorter period of time $(30 \mathrm{~min})$ without the need for special intravenous tubing. The nab-paclitaxel formulation either given weekly or every 3 weeks can achieve $>50 \%$ higher dose than the typical dose used with CrEL-based paclitaxel formulation. Third, nab-paclitaxel was better tolerated than CrEL-paclitaxel with the incidence of grade 4 neutropenia significantly reduced even with a $49 \%$ higher paclitaxel dose administered in nab-paclitaxel.[21] Finally, the response to nab-paclitaxel was shown to be greater than that of Taxol.

Currently, the only commercial dosage form of docetaxel is Taxotere ${ }^{\circledR}$. The Taxotere concentrate is composed of $40 \mathrm{mg} / \mathrm{mL}$ docetaxel dissolved in polysorbate 80 . Taxotere injection concentrate requires two dilutions before administration. The polysorbate 80 in the 
formulation solubilizes docetaxel into water by forming micelles and entrapping docetaxel inside. However, the resulting micellar solution is supersaturated, therefore, the drug ultimately crystallizes over time. For the purpose of physical stability of the product, Taxotere is provided in two vials (one contains docetaxel concentrate and another contains $13 \%$ ethanol in water as a diluent). It requires that the infusion is completed no more than four hours after the dosage preparation. At clinically relevant concentrations, polysorbate 80 significantly increases the fraction of protein-unbound docetaxel due to the high binding affinity of docetaxel to polysorbate 80.[22] As a consequence, polysorbate 80 is associated with alteration of docetaxel pharmacokinetics due to the alteration of docetaxel protein binding profile. Despite the fact that polysorbate 80 influences docetaxel pharmacokinetics, the area under the curve (AUC) of docetaxel was proportional to its dose up to $115 \mathrm{mg} / \mathrm{m}^{2}$, which is different from Taxol.[23, 24] In addition to the drug-induced toxicity, polysorbate 80 itself causes hemolysis and cholestasis.[16]

In August 2010, Sanofi-Aventis announced that the FDA approved a one-vial formulation of Taxotere (1-vial-Taxotere $\left.{ }^{\circledR}\right)$. The one-vial formulation eliminates the need for initial dilution step with the diluent and is ready to be added directly into the infusion solution. The new one-vial formulation is composed of $20 \mathrm{mg} / \mathrm{mL}$ docetaxel in $50 / 50(\mathrm{v} / \mathrm{v})$ polysorbate $80 /$ dehydrated ethanol. The new formulation has the same final drug concentration and the same excipients as the two-vial formulation with the only difference being the alcohol concentration. With 50\% dehydrated ethanol, the docetaxel concentrate is physically stable with reduced viscosity so that it can be directly withdrawn and added to the infusion solution.[25] The one-vial formulation simplifies the manufacture and clinical administration of the drug, but does not solve the issues associated with its excipients.

\subsection{Concerns for taxane delivery and clinical issues}

Paclitaxel and docetaxel administered in their current dosage forms have undesirable pharmacokinetic profiles. The rapid elimination, short half-lives and large volumes of distribution lead to limited drug accumulation in the tumor sites with relatively high drug exposure in normal organs. In addition, the CrEL causes nonlinear pharmacokinetic profile of paclitaxel, which complicates the co-administration of other antitumor agents. Furthermore, rapid elimination of the drugs necessitates inconvenient dosing schedules to realize optimal efficacy.

When administered systemically, adverse effects associated with Taxol and Taxotere include neutropenia, hypersensitivity reactions, fluid retention, peripheral neuropathy, myolosuppression, and gastrointestinal toxicity etc.[23, 26] Among these adverse effects, some of them are inevitable but controllable, such as neutropenia and gastrointestinal toxicity since paclitaxel and docetaxel are potent cytotoxic agents. While some other adverse effects, like hypersensitivity reactions, are clearly vehicle-related and requires premedication of corticosteroids or antihistamines.

The therapeutic index and toxicity of any cytotoxic agent are related to the duration of time that targeted tissues are exposed to a biologically relevant concentration of the drug. The unfavorable pharmacokinetic profile along with high toxicity has a profoundly negative impact on the therapeutic index of paclitaxel and docetaxel. Unfortunately, the excipients in Taxol and Taxotere, namely CrEL, polysorbate 80 and ethanol, not only fail to improve these issues but make them more complicated. Moreover, the limited drug loading in these formulations requires longer infusion time.

The novel CrEL-free Abraxane improved the therapeutic index of Taxol. It almost doubles the response rate and increases time to disease progression (TTP).[21] In addition, it is much better tolerated than Taxol due to its decreased systemic toxicity. However, since the 
complexity of formulation requires recombinant albumin, the cost of Abraxane is comparatively high. Relative to the significantly higher cost, the antitumor efficacy improvement of Abraxane is only marginal. The TTP and patient survival time with nabpaclitaxel are longer than with Taxol but the benefit is only in the time-frame of weeks.

In addition to the low therapeutic index, acquired multidrug resistance remains another major obstacle for the successful chemotherapy of taxanes in the clinic. Multidrug resistance (MDR) is a complex phenomenon often involving multiple mechanisms. Taxane resistance has been attributed to differential expression of various tubulin isotypes, decreased microtubule bundle formation, decreased expression of $b c l-2$, and overexpression of membrane efflux transporter P-gp.[27]

\subsection{Criteria for ideal taxane delivery system}

The ultimate goal of an ideal taxane delivery system is to achieve maximal anticancer efficacy while minimizing or eliminating adverse effects (Figure 2). An ideal delivery system should solubilize the taxanes in an aqueous-based formulation. This would allow for shorter clinical infusion time. In addition, taxanes should maintain a stable therapeutically meaningful concentration in the tumor sites with minimal accumulation in normal tissues. For systemic administration, a high plasma AUC is a prerequisite but may not be sufficient for high tumor accumulation. Considering the short half-life of paclitaxel and docetaxel, the ideal delivery system should protect the taxanes from being rapidly eliminated from the circulation to gain high AUC. To achieve high blood AUC, the formulation needs to maintain two aspects of stability in-vivo: long circulation of delivery vehicles and long retention of taxanes in the delivery vehicles. For long circulation, the delivery vehicle must escape from renal, hepatic filtration and reticuloendothelial system (RES) uptake. The long retention in the delivery vehicles requires high affinity of the drug for the carrier and slow drug release. Only with high drug concentration and prolonged exposure in the blood are these drugs readily available for tumor accumulation over time. Furthermore, to ensure better tumor accumulation, the ideal taxane delivery system should also have some passive or active targeting ability for them to be more specifically distributed to the tumors while minimizing the accumulation in normal organs. Additionally, in terms of adverse effects, the excipients in the formulation should have low toxicity. By optimizing the drug release rate, pharmacokinetics and biodistribution, the delivery vehicle is able to shield or reduce the drug-related systemic toxicity. Another important property of an ideal taxane delivery system is that it could either overcome MDR or prevent MDR from occurring in the first place.

From the manufacturing perspective, the engineering process should be simple, cheap, scalable, and reproducible. The final product should be easy to sterilize with high stability. From a clinical practice standpoint, the formulation should be easy to prepare for administration, ideally requiring only a bolus injection. Finally, for the sake of patients, low cost, shorter infusion time, less frequent dosing, and minimal side-effects are desirable.

\subsection{Anatomy and physiology of tumors and preclinical models to investigate nano-based formulations}

The application of nano-based formulation to deliver anticancer agents is closely related to the distinct physiological and pathological properties of solid tumors. These properties include: abnormal tumor vasculature, increased tumor vasculature permeability, lack of lymphatic drainage, structural changes in interstitial matrix and high interstitial fluid pressure (IFP).[28, 29] These properties create barriers for efficient drug delivery; on the other hand they provide opportunities for nano-based formulation delivery. 
To maintain rapid growth, tumor cells need efficient gas exchange, waste removal, and delivery of nutrients. These rely on the recruitment of new blood vessels caused by a process called angiogenesis. The tumor vessels resulting from rapid angiogenesis are often disorganized with loops and trifurcations clearly different from those in normal tissues.[30] The spatial distribution of tumor vasculature is heterogeneous because angiogenesis is more efficient near the tumor periphery as compared to the center area.[28] The insufficient blood supply to the central region of tumors makes it difficult to deliver drug to this area. On the other hand, the fact that tumor development highly depends on angiogenesis allows for the opportunity to starve tumor cells by cutting off their blood supply.

The vasculature permeability is generally higher in tumors than in normal tissues due to large inter-endothelial junctions, increased numbers of fenestrations and abnormal basement membranes. The pore size cutoff in most tumors ranges from $200 \mathrm{~nm}$ to $1200 \mathrm{~nm}$, whereas a normal continuous endothelium has pore size no greater than $2 \mathrm{~nm}$.[31],[32-34] The difference in endothelial pore size between normal tissues and tumors provides the opportunity for nano-based formulations to selectively extravasate to tumor sites without penetrating to the normal tissues with tight endothelial junctions. However, the leakiness of tumor vasculature is tumor type dependent and location dependent and therefore the drug delivery counting on this structural feature is often unpredictable with high variance. The leakiness of tumor vasculature is partly attributed to a multifunctional cytokine called vascular permeability factor/vascular endothelial growth factor (VPF/VEGF) secreted by tumors.[28] The overexpression of VEGF receptors in the tumor and lining the tumor vessels also offers a potential target for active delivering.

Studies have shown that lymphatic systems inside solid tumors are dysfunctional.[35, 36] The absence of lymphatic drainage causes prolonged retention of macromolecules once they extravasate the leaky vasculature and locate inside the tumors. The enhanced permeability and retention (EPR) effect of macromolecules in solid tumors is a widely accepted concept in nano-based formulation delivery research though recently it is argued that EPR effect is overestimated or artificial.[37] However, despite the fact that the enhanced vessel permeability and impaired lymphatics bring potential benefit to nano-based formulation delivery, they cause another major hurdle to tumor drug delivery, which is increased IFP. The IFP in normal tissues is around $0 \mathrm{mmHg}$ whereas it is significantly elevated to around $20-45 \mathrm{mmHg}$ in various tumors.[38, 39] Studies have shown that the IFP elevation strongly correlates with tumor size and tumor regions.[38] The IFP is lower near the tumor periphery but increases significantly along the tumor cross-section toward tumor central region and the larger tumor is associated with higher IFP. The detrimental outward pressure gradient not only hinders the transvascular drug penetration from blood vessel to the interstitial space but also causes great resistance for transport in the interstitial space with particular difficulties in large tumors.

The tumor interstitial matrix is a space rich in collagen fibers and other additional components, such as proteoglycans and glycosaminoglycans.[40, 41] The mesh-like, tortuous structure of extracellular matrix along with its unique contents leads to high transport resistance to optimal drug delivery. The size, charge and surface properties of macromolecules determine their transport in this space. Apparently, a large particle size is not a favorable property to effectively diffuse through the collagen-rich matrix. The electrointeraction of charged particles with the oppositely charged components in the interstitial space resulting in trapping or aggregation causes another transport hindrance. Particles with flexible configurations likely transport more efficiently than rigid particles of comparable size. Moreover, the compositions and distribution of components are heterogeneous in tumors and between tumor types. Some tumor (area) contains high collagen type I and fibrillar collagen contents while others are with low fiber concentration.[41-43] The 
heterogeneous structure of tumor interstitial matrix also causes heterogeneous drug delivery and variance in different tumor types.

Various preclinical models have been utilized to study the therapeutic efficacy of anticancer agents such as in-vitro cell lines and animal models including human xenograft, mouse allograft, orthotopic and genetically engineered mouse (GEM) model. Preclinical models are useful tools and the rationale of conducting preclinical study is that the preclinical efficacy in cancer models is expected to be predictive of clinical outcomes. However, the predictivity of each model varies. The gap between the preclinical evaluation and clinical results is obvious and largely responsible for the setbacks in this area. Voskoglou-Nomikos et al. compared the clinical predictive value of various preclinical models.[44] Their analysis suggested that, in general, the in-vitro cell line and human xenograft are more predictive than murine allograft models. The in-vitro cell line model shows good predictive ability in the case of typical cytotoxic anticancer agents but not with some non-cytotoxic drugs. The human xenograft model shows good tumor-specific predictive value for NSCLC and ovarian cancers but not for breast and colon tumors. In contrast, the murine allograft model is not predictive of clinical Phase II performance. In addition, the histology/grade of the cancer within a xenograft panel is more important than the number or nature of the xenografts to determine the predictivity of a model. Cancer cells are genetically heterogeneous not only among different tumor-types but also within the same cancer cell line. Therefore, for the cell line-based tumor model, either in culture or xenografts models, the genetic diversity may largely contribute to the variable drug sensitivity, particularly for those directed against specific biomarkers. For cytotoxic agents, preclinical response could also be significantly different due to MDR genotypes. For example, in a sensitive human ovarian cell line OVCAR-8, a paclitaxel nanoparticle formulation showed comparable $\mathrm{IC}_{50}$ value with Taxol, whereas in the P-gp-overexpressing ovarian NCI/ADR-RES, the paclitaxel nanoparticle showed 9-fold higher toxicity owing to its MDR-overcoming properties.[45] Although invivo efficacy study was only conducted with NCI/ADR-RES xenograft, it is expected that the paclitaxel nanoparticle would show similar antitumor efficacy in sensitive cell implants with standard-of-care rather than higher efficacy. Given the high genomic heterogeneity of cancer cells, it is suggested that in the preclinical drug development, a relatively large number of representative cell lines should be covered to adequately capture the genotypedrug sensitivity relationship.[46] Nowadays, the usefulness of xenograft model is still controversial. Many believe that as for cytotoxic agent/formulation development, human xenograft model holds good predictive values, [47-49] whereas for the development of agent directed to specific oncogenic pathways, the xenograft tumors need to be carefully characterized at the molecular level.[50] The major advantages of xenograft models are that they are rapid, reproducible, and cost-efficient. More clinically relevant animal models have been developed more recently to better mimic human disease. For example, as compared to xenograft model, the orthotopic models more closely mimic the primary tumor growth site, morphology, and local invasion. The metastatic properties of some cancers are only observed in orthotopic models but rarely in xenograft models.[51, 52] The resemblance of orthotopic models with clinical diseases is not only at the tissue level, but also at the cellular and molecular levels. The cell growth is stimulated by specific microenvironment and the expression of some important molecules is organ-specific such as gelatinase.[53, 54] More importantly for cytotoxic drug development, the expression of MDR genes is also regulated by the tissue-specific microenvironment such as the extracellular matrix, the presence of growth factors and others.[55-57] The utilization of cell lines expressing reporter genes enables the monitoring of metastasis and therapeutic efficacy by non-invasive imaging technologies.[58, 59] The disadvantage is that the establishment of orthotopic model is often time-consuming and labor-intensive. Several groups reported improved predictivity of orthotopic models over xenograft models.[60-63] However, given the limited data available and lack of comprehensive correlation of orthotopic models with clinical performance, it is 
premature to draw any conclusions about its predictivity. GEM models have been rapidly developed over the last two decades. Primary tumors and metastasis occur spontaneously in GEM models. Compared to the models discussed above, GEM models are better genetically characterized. By utilizing GEM models, not only chemotherapy but also chemoprevention can be investigated. A retrospective study conducted by Dexter et al. revealed that drugs known to be effective in the clinic were also effective against the ras oncogene mouse model; whereas the drugs ineffective in the clinic showed no efficacy in the GEM model as well.[64] Although transgenic models may have better predictive value than transplantable models, they suffer from some disadvantages, which include high cost, low reproducibility, and requirement for large numbers of mouse. However to date, very few studies have reported the use of GEM models for drug/formulation development let alone their clinical predictivity.[65, 66]

\subsection{Nano-based taxane delivery overview}

Nano-based delivery systems have attracted a great deal of attention in the past two decades as a strategy to overcome the low therapeutic index of taxane and delivery barriers in solid tumors. The wide application of nanoparticles in taxane delivery is based on their appealing and unique properties.

First, nano-based formulations provide the physical and chemical protection for water insoluble and labile taxanes. To date, parenteral administration is still the major administration route for highly cytotoxic anticancer agents. Hence, the low solubility of taxanes, vinblastine, and topotecan, limits their optimal clinical application. By utilizing proper nano-materials, poorly water-soluble taxanes could be entrapped in nanoparticles and achieve high concentration in injectable aqueous vehicles.[67, 68] Nano-based formulations also offer protection for chemically unstable drugs by reducing their exposure to water or biological environment. Such examples include camptothecin, SN-38, ATRA, peptides, proteins, and nucleotides.[69-71]

Second, nano-based formulation can improve the pharmacokinetics of anticancer agents. As discussed previously, the improvement of pharmacokinetics relies on the long circulation of delivery vehicles and long retention of anticancer agent in the delivery vehicles. The importance of long circulation of nanoparticles has been widely demonstrated. To achieve long circulation of nanoparticles in-vivo, various PEG-based coatings have been employed. [72-75] It is worth noting that the correlation of in-vitro and in-vivo release behavior is often poor due to the methodology of in-vitro release studies. The slow and sustained release profile in simple aqueous medium such as PBS is misleading in many circumstances. A more biologically relevant release method is crucial to predict the actual in-vivo drug release profile.

Third, nano-based formulations take advantage of the well-known EPR effect and improved the biodistribution of anticancer agents. With a high concentration of drug in the circulation with prolonged period of time, the EPR effect plays a key role in passive targeting of nanoparticles. However, although PEGylation reduces the clearance by the RES, significant accumulation in liver and spleen is still a typical distribution pattern for most nano-based formulations. To further increase the selectivity, active targeting is utilized. The flexible surface chemistry of nanoparticles allows covalent or non-covalent incorporation of targeting ligands. The targeted receptor specifically over-expressed in the tumor cells or site is expected to "attract" more nanoparticles. To date, it is still controversial about whether active targeting truly causes this "homing" effect; however, the internalization is proven to be evidently increased in tumor cells once the drug-loading nanoparticles reach the tumor interstitial space.[76] The passive and active targeting properties of nanoparticles increase the anticancer agent accumulation in tumors while decrease the penetration to normal 
tissues. The superior biodistribution ultimately leads to reduced systemic toxicity and increase efficacy.

Finally, nano-based formulations have the potential to be versatile and multifunctional (Figure 3). Nano-based formulations enable the co-delivery of multiple agents entrapping in the nanoparticles to gain synergistic anticancer effects or multi-functions. Various modifications have been made to the nanoparticle surface as well. According to the application, the nanoparticles can be engineered to be positively-charged or negativelycharged. Active targeting ligands have been covalently attached to the distal end of PEG chain or directly attached to the lipids or polymers. Nanoparticle surface can be chelated with $\mathrm{Ni}$ and incorporate His-tagged antibody/affibody or vaccines.[77, 78]

Myriads of preclinical studies have been focused on developing nano-based formulations to effectively deliver taxanes, one of the most important and most prescribed anticancer drug types in the clinic. Some of these nano-based delivery systems utilize natural carriers such as albumin and lipoproteins.[20,79] while other systems such as polymeric nanoparticles, liposomes, micelles, nanoemulsions, solid lipid nanoparticles, nanocapsules, and dendrimers use synthetic materials. The remaining sections will focus on the advancement on development of lipid-based nanoparticles for taxane delivery.

\section{Types of lipid-based nanoparticles to deliver taxanes}

\subsection{Liposomes}

Liposomal anticancer drugs were the first nano-based formulations approved for cancer therapy by the FDA. The liposomal anticancer drugs approved and marketed for clinical oncology use in the U.S. include Doxil ${ }^{\circledR}$ (doxorubicin), DauoXome ${ }^{\circledR}$ (daunorubicin) and DepoCyt ${ }^{\circledR}$ (cytarabine).

In the development of liposomes to deliver taxanes, increasing drug solubility, decreasing dose-limiting toxicities and altering undesirable pharmacokinetics are the primary goals. The most commonly used preparation method of taxane liposome is simple. The drugs dissolved in an organic solvent are mixed with the lipid excipients dissolved in a miscible organic solvent. The thin lipid film produced by rotary evaporation is then hydrated by adding an aqueous solution. The resultant multilamellar liposomes are extruded through membranes with defined pore size or sonicated to form small unilamellar vesicles with size range 20$150 \mathrm{~nm}$. The stability of liposomes remains one of the most important issues in the development of taxane liposomes. To prepare physically stable taxane liposomes, the lipid composition and the drug to lipid ratio have to be considered and balanced.[80] The most widely utilized lipids in liposome preparation are neutral zwitterionic lipids such as phosphatidylcholine (PC). To minimize aggregation and increase stability, cholesterol or some anionic or cationic phospholipids are often included.[81, 82] The drug-lipid interaction determines the accommodation of water-insoluble taxanes to the lipid bilayer of liposomes. Ideally, a maximal drug to lipid ratio leads to high drug payload and reduces the vehiclerelated toxicities. However, increasing the drug/lipid ratio decreases the physical stability of liposomes in aqueous media.[81] A drug loading of 3-3.5 mol\% (paclitaxel to phospholipid) was physically stable for weeks to months, whereas $4-5 \mathrm{~mol} \%$ paclitaxel was stable in the time range of just several hours to a day, and an $8 \%$ paclitaxel loading only resulted in 15 min of liposome stability. Thereby, to achieve a high drug/lipid ratio while retaining the long-term physical-chemical stability, a freeze-drying method is employed to obtain a dry drug-lipid powder, which is rehydrated in an aqueous solution immediately before use.[83, 84] The physical stability of taxane liposomes can be characterized by measurement of drug retention, circular dichroism spectropolarimetry (CD), differential scanning calorimetry (DSC) and other methods.[85, 86] Besides the physical stability, in-vivo stability is equally 
important if not more important. The long-circulation of liposomes has been realized by sterically stabilizing liposomes using the PEGylation approach.[75] However, a decrease of the physical stability of paclitaxel liposomes has been reported by the incorporation of PEGmodified lipids.[87] It also has been demonstrated that repeated injection of PEGylated liposomes caused accelerated blood clearance of the following injected PEGylated liposomes.[88] The phenomenon is attributed to the abundant IgM secreted by spleen upon first injection. In the clinic, taxanes require repeated doses, therefore this phenomenon may cause potential problems for taxane liposomal formulations. In addition to the stability and drug leakage issues, liposomes have other disadvantages including low loading capacity to lipophilic drugs and the requirement for the use of an organic solvent in the preparation.

Taxane liposomes have shown slower elimination, higher antitumor activity against various murine and human tumors and lower systemic toxic effect compared to Taxol.[89-91] They have also shown antitumor effect in Taxol-resistant tumor models.[83] Cationic liposomes have been prepared from DOTAP and DOPE to encapsulate paclitaxel to selectively target angiogenic tumor endothelium.[92] The paclitaxel-containing cationic liposomes remarkably inhibited the growth of A-Mel-3 tumor while control tumors showed exponential growth. A liposomal paclitaxel formulation composed of cardiolipin, egg PC, cholesterol and D-a-tocopheryl acid succinate (Vitamin E) has progressed to phase-I clinical trial.[93] Unfortunately, despite the promising pre-clinical results, they failed to provide advantages over Taxol in patients with solid tumors.

\subsection{Micelles}

Micelles are the simplest colloidal systems formed spontaneously by amphiphilic molecules. Depending on the types of amphiphilic molecules, micelles can be divided into lipid micelles, polymeric micelles and lipid-polymeric hybrid micelles. For lipid micelles, the amphiphilic molecules are usually small molecular surfactants. Different from the lipid bilayer structure of liposomes, the structure of lipid micelles is a monolayer structure with hydrophilic heads facing the outside aqueous environment and lipophilic tails forming the inner core. The shape of the micelles can be spherical, ellipsoidal or rod-like depending on the composition.[94] At low concentration, the amphiphilic molecules exit in the aqueous media in a separated status. In contrast, when the concentration increases, they start to assemble to a micellar structure driven by the decrease of free energy. The lowest concentration at which micelles are formed is called the critical micelle concentration (CMC). As a simple colloidal system, micellar nano-carriers are utilized in drug delivery fields to mainly deliver hydrophobic drugs, whereas hydrophilic or amphipathic agents are sometimes delivered as well.[95-98] Improving drug solubility is the major rationale of designing micellar nano-carriers. Hydrophobic drugs like taxanes are entrapped in the lipophilic core of the micelles. The commercial dosage forms of paclitaxel and docetaxel, Taxol and Taxotere, can be classified as micelles. However, lipid micellar nano-carriers have two main limitations: relatively low hydrophobic volume of the interior space and dissociation upon dilution in an aqueous or biological environment. Due to the small interior hydrophobic space, the drug loading capacity of lipid micelle is often limited. Also, since the CMC of conventional lipid micelles is often high, they are not stable and tend to dissociate when they are diluted in-vitro or in-vivo. To address these issues, several alternative approaches have been pursued. In the case of Taxol and Taxotere, ethanol is incorporated in both dosage forms to facilitate the drug dissolution and stability. Besides the organic solvent related toxicities, for Taxotere, the micellar solutions after dilution with infusion medium are supersaturated and have to be used in $4 \mathrm{hr}$ before docetaxel begins to crystallize.

In the field of micellar nano-carrier development, a larger amount of studies have focused on the development of polymeric micelles because the CMC values of polymeric micelles are 
extremely low, in the range of $10^{-6}$ to $10^{-7}$ M.[99] To combine the advantages of lipid micelles and polymeric micelles, a novel sterically stabilized micellar (SSM) system composed of poly (ethylene glycol)-grafted distearoylphosphatidylethanolamine (DSPEPEG) was developed to deliver water-insoluble drugs including paclitaxel.[100-102] These phospholipid micelles are biocompatible and easy to prepare. The long acyl chains of DSPEPEG create a large hydrophobic inner core. To further increase the hydrophobic space and improve the solubilization of paclitaxel, another phospholipid, egg PC was incorporated to form sterically stabilized mixed micelles (SSMM) (Figure 4).[97] SSMM solubilized 1.5times more paclitaxel than SSM for the same total lipid concentration. The PEG chains on the surface of these micelles and the strong hydrophobic interactions between the double acyl chains of the phospholipid residues result in lower $\mathrm{CMC}$ and higher thermodynamic stability compared to conventional micelles. The particle size and CMC of these micelles highly depend on the length of PEG chains. With the molecular weight of PEG increased from 750 to 5,000 Da, particle sizes increased from 7-15 nm to $10-35 \mathrm{~nm}$, and CMC decreased from $1 \times 10^{-5}$ to $7 \times 10^{-6}$ M.[103, 104] The paclitaxel-loaded SSM and SSMM were monodispersed with mean particle sizes of $15 \pm 1 \mathrm{~nm}$ and $13.1 \pm 1.1 \mathrm{~nm}$, respectively. Moreover, the PEG chains are also expected to render protection against RES uptake and thus increase drug circulation time in-vivo. Furthermore, the active targeting property can be obtained by conjugating targeting moieties to the distal end of PEG chains. The paclitaxelloaded SSM and SSMM showed similar in-vitro cytotoxicity against human breast cancer MCF-7 with paclitaxel dissolved in 10\% DMSO. However, in a more recent study, it was shown that by adding excessive empty micelles $(1 \mu \mathrm{M})$, the $\mathrm{IC}_{50}$ value of both formulations was about 7-fold lower than that of paclitaxel dissolved in DMSO.[101] This phenomenon provides an idea of preventing micelle rapid breakdown in-vivo by mixing empty micelles as a dilution cushion with drug-loading micelles. To date, there is no direct in-vivo evidence of improved pharmacokinetics or antitumor efficacy for the paclitaxel-loaded micelles over Taxol. The SSM showed increasing circulation half-life with the increase in the size of PEG block.[104] These micelles efficiently and specifically accumulated in Lewis lung carcinoma and EL4 T lymphoma xenografts in mice. It has also been observed that DSPEPEG2000 and DSPE-PEG5000 micelles retained their size characteristics after $48 \mathrm{hr}$ incubation with blood serum at room temperature. The increased drug retention in the micelles is likely associated with the integrity of the micelles. Collectively, these evidences suggest that the SSM or SSMM loaded with paclitaxel has the potential to prolong the drug circulation and achieve efficient tumor accumulation by the EPR effect.

\subsection{Nano-(micro)emulsions}

Emulsions are mixtures of oil(s), water, and surfactant(s). The difference between emulsion and micro-/nano-emulsion is obvious and can be detected by the eyes: emulsions are cloudy suspensions with droplet sizes over $1 \mu \mathrm{m}$, whereas micro-/nano-emulsions are transparent or translucent. However, the misconception about micro-emulsion and nano-emulsion is common in the literature.[105] Many of the systems referred to micro-emulsions in the literatures are actually nano-emulsions, while micro-emulsions are sometimes erroneously considered as nano-emulsions because they have the same apparent structure as nanoemulsions, which is spherical nano-sized droplets dispersed in a continuous phase. The key similarities and differences between micro-emulsion and nano-emulsion are listed in Table 2. Micro-emulsion, as a thermodynamic equilibrium system, is formed spontaneously within the "microemulsion window" by mixing oil, water and surfactant(s) and therefore no energy is needed. To accelerate the emulsification process, in many cases some energy is input to overcome certain kinetic barriers through mechanical stirring or heating.[106] On the contrary, nano-emulsion is in a non-equilibrium state and is generally formulated through the "high-energy" methods such as high-pressure homogenization, ultrasonication, to recruit high energy to breakdown the large droplets to submicron size.[107] Due to the small size of 
nano-emulsions, the sedimentation or aggregation rate is slow so that they are considered kinetically stable. An important property of micro-emulsion are that they are not stable upon dilution because with the aqueous phase increasing, the composition of the water/oil/ surfactant can reach out of the micro-emulsion forming boundary; in contrast, nanoemulsion is stable upon dilution or concentration once it is formed. The better stability of nano-emulsions to environmental stress makes them more suitable for parenteral drug delivery, while micro-emulsions have their applications in oral or topical delivery. Since micro-emulsions and nano-emulsions are both nano-sized drug carriers, their application in taxane delivery will both be reviewed.

An early effort to develop CrEL-free paclitaxel dosage form formulated paclitaxel in an emulsion composed of triacetin as oil phase and soybean lecithin, pluronic F68, and ethyl oleate as surfactants.[108] High-pressure homogenization was utilized to create droplets smaller than $200 \mathrm{~nm}$ with final paclitaxel concentration of $10-15 \mathrm{mg} / \mathrm{mL}$. Later, a vitamin E-based nano-emulsion, TOCOSOL ${ }^{\mathrm{TM}}$, composed of tocopherol (vitamin E) as oil phase, TPGS and Poloxamer 407 as surfactants was prepared by high-shear homogenization.[109] The nano-emulsions had a mean particle size of $62 \mathrm{~nm}$ and could load $8-10 \mathrm{mg} / \mathrm{mL}$ paclitaxel. In-vitro drug release was slow both in the presence and absence of human serum albumin. In the preclinical studies, the paclitaxel-loaded nano-emulsion was well tolerated with 3-fold higher maximum tolerated dose (MTD) over Taxol. It showed superior antitumor efficacy and survival benefit in B16 melanoma mouse model. In the pharmacokinetic studies, it was found that although the blood AUC of paclitaxel nanoemulsion was similar to that of Taxol in B16 melanoma mouse model, the tumor uptake of paclitaxel in nano-emulsion was significantly higher than that of Taxol.[110] The tumor $\mathrm{C}_{\max }$ was 1.5-times higher and AUC was 2.2-times higher after administration of paclitaxel nano-emulsion compared to Taxol. Based on the promising preclinical results, TOCOSOL entered a clinical trial. In phase I, patients received doses up to $225 \mathrm{mg} / \mathrm{m}^{2}$ every 3 weeks. In phase II studies, the efficacy of TOCOSOL was investigated in patients with ovarian cancer, colorectal cancer, NSCL cancer or bladder cancer. In 2007, TOCOSOL was advanced to phase III clinical trial. Unfortunately, phase III studies of TOCOSOL in women with metastatic breast cancer failed to show improvement on objective response rate (ORR) compared to the Taxol arm. In addition, the rates of neutropenia and febrile neutropenia in the TOCOSOL arm were significantly higher than the Taxol arm. Consequently, all clinical trials of TOCOSOL were stopped.

A more recent report used high-pressure homogenization to prepare a nano-emulsion system to deliver docetaxel.[111] The entrapment efficiency determined by ultrafiltration and ultracentrifugation was greater than $90 \%$. The pharmacokinetic study revealed a 3 -fold higher AUC with docetaxel formulated in the nano-emulsion over Taxotere. Another nanoemulsion composed of tricaproin/tricaprylin 3:1, egg PC, and Tween 80 in glycerol solution were developed by first identifying an oil phase with high paclitaxel solubility.[112] It was found that the triglycerols (tributyrin, tricaproin, and tricaprylin) generally had higher solubility to paclitaxel than the natural oils (corn oil, soybean oil, cotton seed oil and mineral oil) selected in the study. By sonication, the resultant nano-emulsions had particle size around $150 \mathrm{~nm}$ and were stable for at least 3 months when stored at $4{ }^{\circ} \mathrm{C}$. The paclitaxelloaded nano-emulsion showed survival benefit over paclitaxel-free nano-emulsion in ascetic-tumor-bearing mice, but whether the formulation had superior antitumor efficacy than Taxol was not investigated.

Nano-emulsions have also been employed to improve the oral bioavailability of paclitaxel. The nano-emulsion was formulated with pine nut oil and egg lecithin by sonication method. [113] After oral administration, a significantly higher concentration of paclitaxel was observed in the systemic circulation from paclitaxel nano-emulsions over a control 
paclitaxel solution. Yin et al. also reported enhanced bioavailability of docetaxel using a micro-emulsion.[114] The micro-emulsion developed with the assistance of pseudo ternary phase diagrams was composed of Capryol 90, CrEL and Transcutol. The micro-emulsion significantly improved the bioavailability of docetaxel (34.4\%) in rats compared to Taxotere (6.6\%) after oral administration. These studies demonstrated a proof-of-concept that nanoemulsion/micro-emulsion could enhance the oral bioavailability of hydrophobic drugs such as taxanes. However, as oral delivery systems of taxanes for practical application, important toxicity issues remain to be thoroughly investigated, because as cytotoxic agents, taxanes are especially toxic to the rapid-proliferating intestinal epithelial cells.

A novel cholesterol-rich nano-emulsion resembling low-density lipoprotein (LDL) was developed by Maranhao et al.[115] LDL is the main carrier of plasma cholesterol in human. In some tumor types, LDL receptor is overexpressed in the neoplastic cells to meet the increased need of cholesterol for new membrane synthesis. Therefore, LDL can serve as a potential drug carrier to specifically deliver anticancer agent to cancer cells overexpressing LDL receptors. However, the isolation and handling of native LDL are difficult. It leads to the design of cholesterol-rich nano-emulsion that resembles the structure of LDL as a vehicle to paclitaxel. The nano-emulsion was prepared from a lipid mixture of cholesteryl oleate, egg PC, triolein and cholesterol. The final nano-emulsion had a mean particle size of $85 \mathrm{~nm}$ obtained by ultrasonication. The radiolabeled nano-emulsion was found to be more rapidly cleared from the patients with acute myeloid leukemia (AML) than in the patients with acute lymphocytic leukemia (ALL).[115] The fact that LDL receptor is overexpressed in AML but not ALL suggests that the cholesterol-rich nano-emulsion was taken up by malignant cells with increased LDL receptor. Later, a lipophilic paclitaxel derivative paclitaxel-oleate was encapsulated into the nano-emulsion. The formulation showed about 2times higher AUC in both mice and patients with gynecologic cancers. $[116,117]$ The $\mathrm{LD}_{50}$ dose of the formulation was 9-times higher than that of Taxol in mice. Its therapeutic efficacy in B16F10 tumor bearing mice was remarkably greater than Taxol in terms of tumor growth inhibition, survival rates and \% cure of treated mice. Another pilot clinical study in nine breast cancer patients also showed more than 3-fold increase of blood AUC compared to Taxol (Figure 5).[118] Both studies conducted in patients with gynecologic cancers and breast cancer showed 3-3.5-times higher drug accumulation in the malignant tumor tissues than in the normal tissues. The paclitaxel-oleate nano-emulsion showed great potential for further clinical development. The idea of constructing LDL-like nano-emulsion to target LDL receptor overexpressing cancer cells was also explored by another group.[119] Instead of making the nano-emulsions cholesterol-rich to resemble LDL, they incorporated a 29-amino acid synthetic peptide containing a lipid binding motif and an LDL receptor binding domain. The in-vitro studies showed that the nano-emulsions containing paclitaxeloleate inhibited the growth of LDL receptor overexpressing GBM cells and demonstrated that the drug was internalized via the LDL receptor.

\subsection{Solid lipid nanoparticles}

Compared to the lipid nano-based formulations discussed above, solid lipid nanoparticle (SLN) is a relatively new colloidal drug delivery system introduced in the early 1990s. Compared to other lipid nano-systems, SLNs have many advantages including ease of preparation and scale-up with low cost, good physical stability, controlled drug release, and versatile chemistry, in addition to others. SLNs can be prepared by high-pressure homogenization, micro-emulsion method, precipitated method by solvent-evaporation, $\mathrm{W} / \mathrm{O} /$ W double emulsion method, and high speed stirring/ultrasonication method.[120] The highpressure homogenizing methods include hot homogenization and cold homogenization. For both techniques the drug is firstly solubilized in the melted lipid. For the hot homogenization technique, the drug-containing lipid melt is dispersed under stirring in a hot aqueous 
surfactant solution with the same temperature. A hot $\mathrm{O} / \mathrm{W}$ nano-emulsion is then obtained through high-pressure homogenizing. SLNs are formed when the hot O/W nano-emulsion is cooled down to room temperature and the lipid recrystallizes. Different from the hot technique, the drug-containing lipid melt is dispersed in a cold surfactant solution for the cold homogenization technique leading to the formation of microparticles. The microparticles are then directly homogenized to nano-sized SLNs at or below room temperature.[121] The high-pressure homogenization method has been scaled up to $2-10 \mathrm{~kg}$ batch sizes under GMP.[122, 123] SLNs can be produced via micro-emulsion. A mixture of lipid, surfactant, co-surfactant and water heated above the melting point of the solid lipid in the micro-emulsion forming region firstly forms a thermodynamically stable micro-emulsion system. SLNs are then formed by dispersing the warm micro-emulsion into a cold aqueous medium under mild mechanical mixing. Mumper et al. developed a warm micro-emulsion precursor process to manufacture SLNs in a one vessel process.[124] The process has been scaled up to 10 liters in the lab and 1 liter under cGMP. For the precipitated method, solid lipid dissolved in an organic solvent is emulsified in a surfactant solution. The lipid precipitates forming SLNs after organic solvent evaporation. The use of an organic solvent is an obvious disadvantage of this method. The W/O/W double emulsion method is a relatively new method developed recently to encapsulate hydrophilic molecules. The highpressure homogenization, micro-emulsion method, precipitation method all have been employed to prepare SLNs to encapsulate paclitaxel and docetaxel.[125-129] A large pool of solid lipids (mono-, di- and tri-glycerides, lipid acids, phospholipids, wax etc.) and surfactants are available for SLN engineering. Among these excipients, some lipids (e.g., glycerides, phospholipids) and surfactants (e.g., Tween 80, lecithin, Poloxamer 188, sodium glycocholate) are acceptable for i.v. injection. The wide availability of i.v.-acceptable solid lipid and surfactant makes SLN a versatile platform for drug delivery readily translational to clinical application although so far there are no SLN products have been introduced into the market for parenteral use. Due to the solid status of the SLN matrix, the physical stability of optimized SLN is generally more than one year.[130, 131]

The drug loading capacity and drug retention in the SLNs are closely related to the solubility and miscibility of drug with the lipid phase, as well as the physicochemical structure of the solid lipid matrix and the polymorphic state of the lipid material.[121] Choosing a lipid with high drug solubility and miscibility is a prerequisite for forming SLN with high drug loading and slow drug release. A paclitaxel-loaded SLN developed by Cavali et al. showed only $0.1 \%$ drug release in PBS in $2 \mathrm{hr}$ following pseudo zero order release.[129] Another paclitaxel-loaded SLN prepared from phospholipid and sucrose fatty acid esters released only 12.5-16.5\% of paclitaxel within 14 days.[132] More impressively, Lee et al. studied the release of paclitaxel from a SLN in $80 \%$ human plasma at $37^{\circ} \mathrm{C}$ using dialysis method. They found that only $10 \%$ of paclitaxel was released from the SLNs in $24 \mathrm{hr}$.[126]

However, the solid lipids with highly organized crystal lattice structure are orderly and tightly packed together leaving very limited space to accommodate large amounts of drug molecules, which leads to low drug loading and burst releases. It has been demonstrated that the extent of burst release is not only associated with the lipid matrix properties, but also is a function of production temperature and surfactant concentration.[121, 133, 134] The initial burst release increases with increasing preparation temperature and increasing surfactant concentration. With higher production temperature and surfactant concentration, the drug solubility in the aqueous phase is higher. During the cooling process of SLN preparation when warm method is used, the drug solubility in the aqueous phase decreases while at the same time the lipid melts solidify and crystallize.[135] The drug re-partitions into the lipids while the lipids increase structural perfection during the cooling, leading to the embedding of drug molecules onto the particle surface and formation of a drug-enriched shell. This unfavorable drug incorporation mode limits the drug loading capacity, and leads to drug 
expulsion during storage and burst release. To overcome this potential issue, Muller et al. proposed a novel lipid nano-system called "nanostructured lipid carriers" (NLC).[135] The NLC is a modification of the conventional SLN by making the solid lipid core a less organized nanostructure. The lipid cores with imperfect crystal structure can be realized by either using spatially different lipids, such as mono-, di-, tri-glycerides with different chain lengths, or mixing some liquid lipids (oils) with the solid lipid. The space between different fatty acid chains and crystal imperfections provide more accommodation for drug molecules. In addition, some drugs have higher solubility in oils than in solid lipids. Therefore, the NLC as a new generation of SLN increases the drug payload and decreases drug expulsion and burst release. Besides the lipid matrix, it is also possible to tune the release profile by adopting different production method (warm or cool) or modifying surfactant concentration. Finally, it is worth noting that burst release may not be necessarily a bad property for all drugs. When an initial high blood concentration is desirable according to the therapeutic needs, the burst release can be useful under more precise control.

The in-vitro uptake and cytotoxicity of paclitaxel-loaded SLNs have been demonstrated in several cell lines.[45, 126, 127, 136] The lipid matrix materials seem to not only influence drug release rate but also affect cellular uptake as well. Yuan et al. investigated the cellular uptake of several SLNs composed of different lipid materials including monostearin, stearic acid, glycerol tristearate and Compritol 888 ATO (ATO888).[136] Their results showed that the cellular accumulation preference was in the order of glycerol tristearate SLN > monostearin SLN> stearic acid SLN> ATO888 SLN. This is explained by different affinity between fatty acids and cell membrane. Moreover, the PEGylated stearic acid SLN showed the highest cellular uptake among the materials tested. Paclitaxel loaded in these SLNs showed 1.6-10-fold higher cytotoxicity compared to Taxol. SLNs encapsulating paclitaxel not only showed higher anticancer activity in sensitive cell lines, but also overcame MDR in $\mathrm{P}$-gp overexpressing cells. In a P-gp-overexpressing human ovarian carcinoma cell line NCI/ ADR-RES, SLN G78 containing paclitaxel showed 9-fold lower IC $_{50}$ value.[45] The potential mechanism of overcoming P-gp-mediated MDR was also investigated. It was demonstrated that the surfactant Brij 78 used in the SLN G78 temporarily decreased ATP level in resistant cells, thus the energy-dependent P-gp efflux was transiently inhibited. The increased uptake of high drug payload SLNs by endocytosis along with the inhibition of Pgp function resulted in greater cellular uptake and higher cytotoxicity in resistant cells. The blank SLNs themselves were well-tolerated both in-vitro and in-vivo. In-vitro experiments showed that SLN E78 did not cause blood cell lysis at concentration up to $1 \mathrm{mg} / \mathrm{mL}$ and did not activate platelets.[137] In-vivo i.v. bolus injections of cetyl palmitate SLNs into mice at dose up to $1.33 \mathrm{~g} / \mathrm{kg}$ with 6 repeats did not cause acute toxicity or increase in liver and spleen weight.[121]

SLN encapsulation improves drug pharmacokinetics and biodistribution. Similar to other nanoparticles, the long-circulation of SLNs can be achieved by modifying the particle surface with more hydrophilic moieties to evade RES clearance. The most widely used method is PEGylation. As compare to other more well-established nano-systems such as liposomes, the development of stealth SLNs is still in its initial phase. Also due to the great diversity of SLNs, there are no certain rules and approaches that can be universally applied to all or most of the SLNs in terms of coating density, chain length and incorporation method. To date in the literature, stealth SLNs are PEGylated through either PEG-grafted lipids (e.g., DSPE-PEG2000, stearic acid-PEG) or surfactants with certain PEG chains (e.g., Brij 700, TPGS). Two long-circulating SLNs containing paclitaxel were developed and their pharmacokinetics were evaluated in mice by Chen et al.[125] Both of the two SLNs were composed of stearic acid and lethicin as oil phase, with Brij 78 as surfactant in one formulation (Brij78-SLN) and Poloxamer F68 and DSPE-PEG2000 in another (F68-SLN). Brij78-SLN and F68-SLN increased paclitaxel AUC 1.7-fold and 1.9-fold compared to 
Taxol, respectively. The longer PEG chain of DSPE-PEG2000 (Mw 2000) compared to Brij 78 (Mw 1200) may be responsible for the slightly longer circulation and higher AUC of F68-SLN. Interestingly, non-stealth SLNs without PEGylation also enhanced systemic circulation of encapsulated drugs.[138-142] The mechanism of this unique characteristic of SLN is not clear. It is possible that some surfactants used in the so-called non-stealth SLNs carry similar properties as PEG. For example, Poloxamer used in the study of Yang et al. is a triblock copolymer composed of a central hydrophobic chain of polyoxypropylene flanked by two hydrophilic chains of polyoxyethylene.[142] Another example is vitamin E-TPGS (alpha-Tocopheryl Polyethylene Glycol 1000 succinate) which has a medium PEG chain with molecular weight of 1000 . These surfactants may result in a hydrophilic shield on the SLNs to protect them from RES uptake. However, in more cases, this explanation may not apply. Further thorough investigations are needed to fully understand the underlying mechanism. Up till now, a considerable accumulation of SLNs in the organs of RES (liver, spleen, and lung) is still a typical distribution pattern after i.v. injection of either non-stealth or stealth SLNs. With prolonged exposure in systemic circulation, SLNs deliver more entrapped drugs to solid tumor tissues taking advantage of the EPR effect.[143] An extraordinary finding by many research groups revealed that SLNs improved the delivery of various drugs to brain.[139, 140,142,143] One potential explanation of the effect is that plasma proteins (e.g., apolipoproteins) bind to particle surfaces and mediate adherence to blood-brain-barrier (BBB) endothelial cells.[120] The BBB endothelial cells are famous for their tight junctions and high expression of P-gp. Brain uptake of paclitaxel nanoparticles was evaluated by Koziara et al. using an in-situ rat brain perfusion model.[144] Their results suggested that entrapment of paclitaxel in SLNs significantly increased the paclitaxel brain uptake. Possible mechanisms of increased brain delivery of these SLNs include: 1) shielding of drug from direct interaction with P-gp by nanoparticle entrapment, 2) modulating of BBB $\mathrm{P}$-gp function by the surfactant (Brij 78), and 3) triggering of endocytosis/trancytosis. These data suggest the possibility of brain delivery of chemotherapy with SLNs.

\subsection{Nanocapsules}

Nanocapsules are defined as nano-scaled particles with an oil core surrounded by a rigid shell. With the liquid oil core as a drug reservoir and rigid shell as a drug leaking barrier, nanocapsules are expected to have high drug encapsulation capacity, good drug retention and high stability. Similar to SLNs, nanocapsules are generally stable over a year. They have fewer drug leakage problems associated with liposomes and avoid drug expulsion problems associated with SLNs. There are two types of nanocapsules, based on the structure and components of the shells: polymer-shelled nanocapsule and surfactant-shelled nanocapsule. The preparation of both polymer-shelled nanocapsule and surfactant-shelled nanocapsule is closely related to nano-emulsion/micro-emulsion. Polymer-shelled nanocapsules can be prepared by interfacial polymerization, salting-out, emulsification-diffusion, and nanoprecipitation.[107] For the interfacial polymerization method, nano-emulsion droplets serve as individual nano-reactors, on the surface of which polymerization of monomers with different mechanisms occur and form polymeric shell encapsulating liquid oil core and drugs.[145-147] Different from interfacial polymerization technique, the latter three methods disperse preformed polymer on nano-emulsion surface. The latter three methods were compared by Galindo-Rodriguez et al.[148] Methacrylic acid copolymer and poly(vinyl alcohol) (PVA) were selected as polymer and emulsifying agent to prepare nanocapsules utilizing all three methods. The size distribution of nanocapsules prepared by nanoprecipitation was narrower than those by salting-out and emulsification-diffusion methods. The factors influencing nanocapsule formation by salting-out and emulsificationdiffusion methods were PVA chain interactions at the interface and in the bulk solution; while the parameter governing the nanocapsule characteristics from nanoprecipitation method was water-solvent interaction. All the methods for polymer-shelled nanocapsule 
preparation involve the use of organic solvent. Nanocapsules have been developed to deliver paclitaxel since 20 years ago.[149] Unfortunately, the mice treated with $1.5 \mathrm{mg} / \mathrm{kg}$ paclitaxel-loaded nanocapsules died before control mice, suggesting high toxicity of the nanocapsules which was composed of poly(lactic acid), benzyl benzoate and Pluronic F68. Over the past 20 years, the development of nanocapsules for anticancer drug delivery is fairly slow compared to other lipid-based nano-carriers. Until more recently, several polymer-shelled nanocapsules are reported for paclitaxel delivery with only in-vitro studies. Nanocapsules were prepared using a freeze-drying method to directly disperse Pluronic F-127 triblock copolymer to the surface of lipid core composed of lecithin and paclitaxel. [150] The paclitaxel-loaded lipid cores dispersed in $10 \mathrm{wt} \%$ F-127 aqueous solution exhibited droplet size of $99 \mathrm{~nm}$. However, after the freeze-drying to induce the formation of polymeric shell, a mean particle size of $267.4 \mathrm{~nm}$ and broad distribution were observed. The large particle size and broad distribution may cause potential risks for parenteral application. PEO-PPO-PEO/PEG shell cross-linked nanocapsules were prepared by dissolving an oil $\left(\right.$ Lipiodol $^{\circledR}$ ) and an amine-reactive PEO-PPO-PEO derivative in DCM and consequently dispersing in an aqueous solution containing amine-functionalized six-arm-branched PEG by ultrasonication.[151] The resultant nanocapsules had an average particle size of $110 \pm 9.9$ $\mathrm{nm}$ with paclitaxel-loading efficiency of $46.5 \pm 9.5 \%$. Zhang et al. prepared nanocapsules through interfacial polymerization of butylcyanoacrylate (BCA) with PEG as initiator.[152] The particle sizes, paclitaxel entrapment and hemolytic potential of PEG-PBCA nanocapsules were all related to the quantity and molecular weight of mPEG. With longer PEG chain length, mPEG5000 served as a stronger stabilizer and formed smaller nanocapsules compared to mPEG2000. The encapsulation efficiency of paclitaxel also increased with increase of PEG concentration. The 10\% (w/v) PEG-PBCA nanocapsules showed about $60 \%$ of paclitaxel encapsulation efficiency. With the increase of PEG concentration, the hemolysis rate decreased as well. Generally, the encapsulation efficiency of paclitaxel in polymer-shelled nanocapsules is not very high so far.

The surfactant-shelled nanocapsules are prepared by phase inversion temperature (PIT) method. PIT method is based on the changes in solubility of the polyoxyethylene-type nonionic surfactant with temperature. At temperature below the PIT, the surfactant monolayer has a positive curvature forming $\mathrm{O} / \mathrm{W}$ emulsions; while above the PIT, the curvature becomes negative forming W/O emulsions. During the preparation of nanocapsules, the mixture of all components is heated to above the PIT (T2) then cooled to temperature below PIT (T1). Several temperature cycles between $\mathrm{T} 1$ and T2 are carried out followed by a sudden dilution with cold water to induce an irreversible shock. This method developed by the Benoit group generally uses capric and caprylic acid triglycerides as the oil phase, and a small amount of Lipoid ${ }^{\circledR}$ as the hydrophobic surfactant. $[153,154]$ The leading role is played by the hydrophilic surfactant Solutol ${ }^{\circledR}$ HS 15, which is a mixture of free PEG 660 and PEG 660 hydroxystearate. The nonionic surfactants finally crystallize since the final temperature is below their melting point (about $30^{\circ} \mathrm{C}$ ), leading to the formation of a rigid shell. The shell is structured as a combination of hydrophobic surfactant (Lipoid) anchoring in the oil phase and hydrophilic surfactant (Solutol) orienting toward the aqueous phase. The percentage of Solutol and the number of temperature cycles have major influence on particle size and size distribution. With higher percentage of Solutol and more temperature cycles, the particle size decreases and size distribution becomes narrower. Paclitaxel was encapsulated in the surfactant-shelled nanocapsules by the same research group. The entrapment efficiency in these nanocapsules was $99.9 \%$. The pharmacokinetics and biodistribution of radiolabeled blank nanocapsules were studied.[155] The $\mathrm{t}_{1 / 2}$ and MRT values of nanocapsules (2-3 hr) indicated long circulation of the nanocapsules. The pharmacokinetics of paclitaxel-loaded nanocapsule was missing. However, the slow release of paclitaxel from the nanocapsules invitro along with the long-circulation of blank nanocapsules in-vivo suggested the potential of improved paclitaxel pharmacokinetics.[156] The antitumoral activity of paclitaxel-loaded 
nanocapsule was evaluated in a chemically induced hepatocellular carcinoma (HCC) model. Animals treated with $4 \times 70 \mathrm{mg} / \mathrm{m}^{2}$ of paclitaxel-loaded nanocapsules showed significant increase in the mean survival time compared to the blank nanocapsule and saline groups but with no statistical significance compared to the Taxol group.[155] The antitumoral activity was also studied in a glioma model with MDR.[156] Paclitaxel-loaded nanocapsules significantly lowered both the tumor mass and tumor volume growth; whereas Taxol treatment showed no significant effect. The potential mechanisms of overcoming MDR by these nanocapsules were inhibition of MDR efflux pump by PEG-HS and redistribution of intracellular cholesterol. These nanocapsules were also administered orally to enhanced the oral bioavailability of paclitaxel.[157] The AUC of paclitaxel-loaded nanocapsule was 3fold higher in comparison to the AUC of Taxol group, and comparable to the Taxol + verapamil group. The improvement of oral paclitaxel bioavailability when it was loaded in nanocapsules was likely due to the inhibition of P-gp by nanocapsules. Another research group prepared nanocapsules using the same PIT method to deliver docetaxel to solid tumor. [158] Encapsulation of docetaxel in the nanocapsule increased its AUC in blood and in tumor 4-fold and 5-fold, respectively, compared to Taxotere. The pharmacokinetics and biodistribution profiles were found to depend on PEG density on the particle surface. PEGylation of nanocapsules with DSPE-PEG2000 at 6,10 and 15 mol\% greatly enhanced nanocapsule circulation time. The highest blood concentration of docetaxel $2 \mathrm{hr}$ postinjection was obtained with $120 \mathrm{~nm} 15 \mathrm{~mol} \%$ PEG nanocapsules. Tumor accumulation seemed to increase with PEG density but not statistically significant until $12 \mathrm{hr}$ only between $6 \%$ and $15 \%$ of PEG groups.

\subsection{Prodrug strategy for better lipid nanoparticle encapsulation}

Various paclitaxel and docetaxel prodrugs have been designed by conjugating small molecules, polymers, or targeting ligands etc. to realize different goals such as increasing water-solubility, site-specific release and tumor targeting.[159] In this section, we only focus on the prodrug strategies to manipulate the taxane hydrophilicity/hydrophobicity to be better incorporate them into different lipid nano-carriers.

Most lipid-based nanoparticles are designed to be more suitable and efficient for the encapsulation of lipophilic drugs. However, one significant problem with these systems are that the lipophilic drugs are often released very quickly from the nanoparticles in-vivo due to the rapid partition of the drugs into the blood due, in part, to high protein binding. This issue is often neglected or unappreciated because most of the in-vitro release experiments are performed in simple aqueous solutions like PBS and have poor prediction of the in-vivo release behaviors. To address this potential issue, lipophilic taxane prodrugs were synthesized to further increase their lipophilicity and miscibility with lipids. Stevens et al. synthesized paclitaxel-7-carbonyl-cholesterol (Tax-Chol) and evaluated its incorporation into a nano-emulsion formulation.[160] Tax-Chol was incorporated into the nano-emulsion with greater than $90 \%$ entrapment efficiency. The release of Tax-Chol or paclitaxel from the nano-emulsions was determined in $45 \mathrm{mg} / \mathrm{mL}$ bovine serum albumin (BSA). The release of Tax-Chol was significantly slower than that of paclitaxel from the nano-emulsion. Paclitaxel was modified by attaching an oleoyl group to mimic cholesteryl esters and enhance its incorporation and retention in LDL-resembling nano-emulsions by several groups.[116, 119, 161] The paclitaxel-oleate demonstrated significant greater incorporation into nanoemulsions compared to unmodified paclitaxel.[119] These paclitaxel-oleate nano-emulsions showed promising in-vitro properties as well as in-vivo pharmacokinetics. To enhance the solubility of docetaxel in Labrafac ${ }^{\mathrm{TM}}$ (propylene glycol dicaprylate/dicaprate), a docetaxel prodrug was synthesized by attaching a lauroyl group to docetaxel through an ester link. [162] The $2^{\prime}$-lauroyl docetaxel showed greater than 8-fold solubility in the oil compared to unmodified docetaxel. In a nano-emulsion using Labrafac as the oil phase, $2^{\prime}$-lauroyl 
docetaxel showed high loading capacity $(5.7 \% \mathrm{w} / \mathrm{w})$ and high entrapment efficiency (97\%). Since medium chain glycerides are widely used in formulating various nano-emulsions, micro-emulsions and nanocapsules, this strategy has its potential application in a number of nano-carriers. Ali et al. synthesized a series of paclitaxel prodrugs with 2-bromoacyl chains ranging from $6,8,12,14$ to 16 carbons in length.[163] For comparison, hydrophobic paclitaxel prodrugs in acyl chain lengths from 6 to 16 without bromine at the 2-position were also synthesized. In-vitro, the cytotoxicity decreased with the increase of acyl chain length. In general, the taxanes lacking bromine were 50- to 250-fold less active than their bromoacyl counterparts indicating that the electron-withdrawing group facilitated the cleavage of active paclitaxel. The 2-bromoacyl taxanes were formulated into liposomes and evaluated for their anticancer efficacy in an ovcar-3 ovarian mouse model. In-vivo results showed that prodrugs with a longer chain were therapeutically more efficacious than those with a shorter chain, which was opposite to the in-vitro cytotoxicity. The trend was probably explained by slower release and hydrolysis in the systemic circulation leading to higher accumulation in the tumor site for prodrugs with a longer chain.

Conversely, more hydrophilic conjugates of taxes have been explored to better to improvement entrapment in liposomes. For example, a water-soluble paclitaxel prodrug was synthesized by the covalent attachment of a methacrylic acid based oligomer with molecular weight of 1657 Da to paclitaxel.[164] The optimized liposomal formulation encapsulated 3 mol\% of paclitaxel prodrugs with entrapment efficiency of $91 \%$. In $180 \mathrm{hr}, 45 \%$ prodrug release was observed in saline. However, as a prodrug, it did not release paclitaxel efficiently both in-vitro and in-vivo. In rat plasma, less than $1 \%$ of paclitaxel was liberated from the prodrug in $24 \mathrm{hr}$. Another study developed a weak-base derivative of docetaxel, $2^{\prime}$ O-(N-methyl-piperazinyl butanoyl) docetaxel.[165] The weak-base prodrug was actively loaded into liposomes using $\mathrm{pH}$ gradient loading techniques and achieved stable drug encapsulation and retention. In-vitro cytotoxicity study in several cancer cell lines showed similar activity as unmodified docetaxel, suggesting efficient converting of prodrug to active parent drug. The prodrug formulated in liposomes extended the circulation half-life to about $10 \mathrm{hr}$ with 50-100 times higher plasma exposure compared to Taxotere or docetaxel derivative formulated in the Taxotere vehicle (Figure 6). The MTD of liposomal prodrug was 3-fold higher than that of Taxotere. In a human breast cancer (MDA-MB-435/LCC6) xenograft model, at equimolar dose $(25 \mathrm{mg}$ docetaxel $/ \mathrm{kg})$, the liposomes and Taxotere had similar activity; while at dose level of $88 \mathrm{mg}$ docetaxel $/ \mathrm{kg}$, the drug-loading liposomes was much more efficacious.

It has been established that $2^{\prime}-\mathrm{OH}$ of both paclitaxel and docetaxel is more reactive than the $7-\mathrm{OH}$ or other hydroxyl groups and the $2^{\prime}-\mathrm{OH}$ is critical for microtubule binding and cytotoxic effects.[166] In contrast, 7-OH is not as essential for the cytotoxicity of taxanes as $2^{\prime}-\mathrm{OH}$ but derivatives at 7-OH position are very stable under physiological conditions.[167, 168] As a result, derivatives of taxanes are almost always carried out at $2^{\prime}-\mathrm{OH}$ generating less toxic taxane prodrugs. Besides the improvement of drug encapsulation in lipid nanocarriers, taxane prodrugs have other advantages such as reduced systemic toxicity and potential of site-specific release of active drugs depending on the conjugation chemistry. If the conjugation linkage is cleaved by some enzymes specifically expressed or overexpressed in tumor site, it will lend the prodrug formulation extra targeting properties and further enhanced therapeutic index. The prodrug strategies benefit taxane delivery in many aspects, but at the same time complicates taxane delivery in terms of drug release profile. In addition to the drug release from formulations, active drugs need to be liberated from the prodrugs as well. Problems can be caused by either premature cleavage and release of active drugs, or too slow cleavage and inefficient liberation of active drugs. Therefore, when designing taxanes prodrug, a suitable drug cleavage rate is critical. 


\section{Active targeting of taxane lipid-based nanoparticles}

Passive targeting of nanoparticle is based on the unique property of nanoparticles as well as the unique physiology and microenvironment of solid tumors. Nano-scaled particles preferentially accumulate in solid tumors taking advantage of the EPR effect. Different from passive targeting happening in tissue level, active targeting is based on specific molecular recognition, binding and the following endocytosis. The active targeting property can be intrinsic due to the nature of the nanoparticles. For example, cholesterol-rich nanoparticles target LDL receptors due to their components and structure resembling native LDL.[115] Cationic liposomes prepared from DOTAP and DOPE selectively target angiogenic tumor endothelium.[92] There are only a few examples of "build-in" active targeting, but it represents an inspiring alternative of conventional active targeting strategy. The most commonly used active targeting strategy is to graft targeting ligands such as antibody, peptide, small molecules, or aptamer on the surface of nanoparticles. Because nanoparticles usually carry high payload of anticancer agents, fewer ligands are required to achieve high active targeting efficiency compared to other delivery systems such as drug-ligand conjugate. Choosing a suitable target as well as targeting ligand is critical for the successful active targeting therapeutics. Ideally, the expression of the receptor on the target cells should be highly specific with high expression level in majority of the target cells. In reality, it is almost impossible that the receptors only express in malignant cells. Higher tumor to normal tissue expression ratio provides higher selectivity. The major molecular targets for active targeting strategy include three types: angiogenesis-associated targeting (e.g., VEGFReceptor), uncontrolled proliferation targeting (e.g., transferring receptors, folate receptors) and tumor cell targeting (e.g., HER-2, asialoglycoprotein receptor).[169] The targeting ligand should have high affinity with the target receptor to ensure sufficient retention time as well as trigger cellular uptake via receptor mediated endocytosis instead of remaining bound to the receptor. Furthermore, the targeting ligand should be amenable to the required chemistries to attach the ligand to the nano-carrier. To avoid spatial shield, targeting ligands are usually conjugated to the distal end of PEG chains. The incorporation method of PEGligand includes pre-insertion and post-insertion methods. The pre-insertion method is to mix functionalized lipid-PEG with other components and prepare nanoparticles first, and then covalently graft targeting ligands to the nanoparticle surface. The post-insertion method is to prepare nanoparticles first followed by mixing with preformed lipid-PEG-ligand conjugate. Alternatively, the preformed lipid-PEG-ligand conjugate can be directly mixed with other components and prepare nanoparticles.

During the development of active targeting nanoparticles, several factors must be taken into consideration. From the targeting ligand point of view, the conjugation chemistry and preparation conditions should not alter their binding affinity. The functional group or structure essential for receptor recognition and binding should not be abolished or shielded due to the coupling to PEG. For some antibodies or peptide ligands, certain configuration must be retained to keep their binding affinity. Thus, depending on their sensitivity to environment, preparation conditions such as high temperature or the involvement of organic solvent should be avoided or used with extra caution. On the other hand, the incorporation of targeting ligand should not negatively change the properties of nanoparticles in terms of particle size, drug loading, drug release profiles and in-vivo elimination rate. Moreover, the targeting ligand should stably associate with the nanoparticles until they reach the targeting sites. However, in some types of lipid-based nanoparticle such as liposomes, the lipids are in constant exchange with the environment that they in contact such as cell membranes. Consequently, there is a potential risk of losing active targeting ligands in biological condition. Finally, defining optimal density of targeting ligand on the nanoparticles is another important task. High ligand density in a feasible range may increase target binding, yet higher than optimal density may cause issues like higher cost, or aggregation. 
The folate receptor is one of the mostly used targets for active targeting therapeutics. The folate receptor is significantly upregulated in many cancer cells including ovarian, lung, brain, head and neck, and breast cancers.[170,171] What makes the folate receptor an interesting target is that normal cells use reduced-folate carrier pathway that only transports reduced-folate but not folate conjugates of any type, while folate-conjugated nanoparticles can only use folate receptor pathway which has high specificity in malignant cells.[170] Folic acid has a very high affinity for folate receptor $\left(\mathrm{Kd} \sim 10^{-10}\right)$. As small molecule, folic acid has many advantages over antibody ligand including small size, non-immunogenicity, non-toxicity, ease to handle and conjugate to carriers, high stability in preparation, storage and circulation, and low cost. Folic acid has been conjugated to liposomes,[172] SLNs,[136] nanocapsules,[151] nano-emulsions[160] and core/shell nanoparticles[173] for paclitaxel and docetaxel targeted delivery. Wu et al. developed a folate receptor-targeted liposome and demonstrated efficient uptake by KB cells, which have high folate receptor expression.[172] The targeted liposomes containing paclitaxel showed 3.8-fold greater cytotoxicity compared to non-targeted liposomes in KB cells. The in-vivo half-life of targeted liposomes was comparable to that of non-targeted liposomes and both were much longer than the half-life of Taxol (7- to 8-fold). Studies by Bae et al. revealed significantly enhanced cellular uptake and cytotoxicity of a folate-conjugated nanocapsule in KB cells using confocal microscopy and flow cytometric analysis.[151] Enhanced cellular uptake and cytotoxicity were also observed for a folate-conjugated core/shell nanoparticle containing docetaxel in MCF7 cells. [173] In a folate receptor overexpressing A549 cell line, paclitaxel-loaded SLNs modified with folic acid-stearic acid enhanced the cellular uptake and cytotoxicity 2-fold and 8.8-fold compared to non-targeted SLNs, respectively.[136] Steven et al. delivered folate-conjugated nano-emulsions containing a paclitaxel lipophilic prodrug to mice bearing M109 tumors. Significantly greater tumor inhibition and animal survival were observed for targeted nanoemulsion treatment group compared to treatment with non-targeted nano-emulsions or Taxol.[160]

Asialoglycoprotein receptor (ASGP-R) is a promising receptor for liver targeting. Xu et al. designed SLNs using a galactose moiety to target ASGP-R.[174] In in-vivo efficacy studies, mice bearing hepatoma were treated with $10 \mathrm{mg}$ docetaxel $/ \mathrm{kg}$ once a week for three weeks with targeted SLNs, non-targeted SLNs or Taxotere. The targeted SLNs demonstrated the most dramatic efficacy with complete tumor regression in all six mice (Figure 7). The outstanding antitumor efficacy of targeted SLNs was attributed to both increased accumulation in tumor indicated by biodistribution study and more cellular uptake by hepatoma cells demonstrated by confocal images.

Overexpression of epidermal growth factor receptor (EGFR) has been detected in one third of all solid tumors, in many of which EGFR expression characterizes a more advanced disease stage.[175] Docetaxel nanoparticles modified with recombinant human EGF showed improvement of cell internalization and higher cytotoxicity against MDA-MB-468 cells. [176] In BALB/c mice bearing MDA-MB-468 tumor xenografts, targeted nanoparticles exhibited stronger inhibition of tumor growth compared to non-targeted nanoparticles or Taxotere. At a dose of $10 \mathrm{mg}$ docetaxel $/ \mathrm{kg}$, tumor disappeared completely in the targeted nanoparticle treatment group. The dramatic antitumor activity was also consistent with the 3.6-times higher AUC over that of Taxotere and significantly higher tumor accumulation compared to non-targeted nanoparticles.

Vasoactive intestinal peptide (VIP) receptor is a relatively new target investigated for active pharmaceutical targeting. VIP receptors are found in high densities in human lung and breast cancers. [177, 178] VIP has been grafted to sterically stabilized micelles.[101, 179] The invitro internalization of VIP-grafted micelles in human MCF-7 breast cancer cells and increased cytotoxicity in drug resistant BC19/3 cells have been established. So far, in-vivo 
pharmacokinetics and antitumor efficacy data are still lacking, and a thorough understanding of VIP expression specificity in tumors compared to normal tissues remains to be mapped out.

Nowadays, there are existing controversies about whether targeting ligand influence nanoparticle tumor localization or uptake. There exist conflict observations in the literature. Some studies being discussed previously in this review as well as others reported enhancement of tumor accumulation, whereas others believe that ligand only increases tumor cellular uptake instead of tumor localization. Pirollo et al. proposed explanations for the conflict observations based on the detailed review of three studies.[180] Their hypothesis is that the presence or absence of PEG makes a difference. In the works of Barlette et al. [181] and Kirpotin et al.[182], they used PEGylated nanoparticles with or without target ligands. PEGylation already achieved great improvement of nanoparticle circulation time which in turn increases tumor accumulation by the EPR effect so that further increase in tumor localization attributed to active ligand is masked. Conversely, when PEG chains are absent as in the reports of Wu et al.,[183] the contrast becomes more apparent. However, the PEG theory does not apply to many other cases. Hussain et al. reported a 2-fold tumor accumulation of EpCAM-targeted liposomes over non-targeted liposomes loaded with doxorubicin in mice bearing SW2 tumor xenografts.[184] In this study, both targeted and non-targeted liposomes are PEGylated. For some nano-delivery systems, active target ligand alters nanoparticle surface property so that the clearance is reduced. It was reported that the transferrin on the surface of positively charged polymeric nanoparticles shielded some charges so that the elimination associated with the non-specific interactions was decreased and passive targeting was increased.[185] It seems that the so-called "active targeting" is not that the ligand on the nanoparticles actively searches for its target in the circulation and directs the localization of its cargo; instead, active targeting is essentially an EPR effect with reinforced retention effect due to the ligand-target binding. Whether targeting ligand truly enhances active targeting nanoparticle tumor localization is a very complicated issue. In addition to PEGylation and nanoparticle surface properties, other factors such as target ligand type and property, ligand-target interaction and tumor type also play critical roles in this issue. To date there is no single theory that can be generalized to all observation conflicts. Comprehensive researches are definitely needed for a more complete understanding. Despite the controversy about target ligand's essential function, enhanced therapeutic efficacy with targeted nanoparticles is commonly reported. The improvement of anticancer efficacy is explained by 1) active targeting ligand mediates endocytosis thus increases cellular accumulation of anticancer agents, and 2) some active targeting antibodies carry anticancer activity by their own such as anti-EGFR antibody. The ligand-mediated endocytosis is particularly important for nucleotide (e.g., siRNA, oligonucloetide) delivery.

Inclusion of active targeting moieties in nano-based formulations renders them enhanced specificity and selectivity for delivery of anticancer agents to tumors. However, a great deal of effort still need to be made to address many issues such as immunogenicity, toxicity, cost, scale-up difficulties, etc., especially for antibody-based active targeting of nanoparticles.

\section{Advantages and disadvantages of lipid-based nanoparticles compared to other nano-delivery systems}

Polymeric nanoparticles are another major class of nano-based system for taxane delivery. Because polymeric materials are synthetic, they can be designed to offer a more versatile structure and more functionality for linking various ligands to the surface of the colloidal systems. To date in the literature, more active targeting researches use polymeric nanoparticles as compared to lipid-based nanoparticles. One of the potential reasons is the higher stability of the targeting ligands on the polymeric nanoparticles both in-vitro and in- 
vivo over lipid-based nanoparticles. Polymeric micelles compared to conventional lipid micelles, are more stable due to their lower CMC. However, polymeric nanoparticles still lack a suitable and cost-efficient scale-up production method; while large scale production methods of lipid-based nanoparticles such as liposomes and SLNs are readily available. Lipid nanoparticles are generally less toxic than polymeric systems attributed to their natural property.[186] A comparative study demonstrated that the highest toxicity was observed for the faster degrading polymers, low molecular weight PLA and PLGA, and the least toxic effects were observed for SLNs.[187] The toxicity may partly attribute to the acidic degradation products by these polymers.[188] In addition, the preparation of polymeric nanoparticles almost always involves organic solvent which causes more production and toxicity issues. Most of the dendrimer carriers covalently graft taxanes to their surface functional groups.[189, 190] Very few of them physically solubilize taxanes.[191] As a special type of polymer, dendrimers share the disadvantages of other polymers. Moreover, the covalent conjugation makes dendrimer carrier production even more complicated and difficult to scale up.

Natural macromolecules account for another class of taxane delivery nano-carriers. The currently marketed paclitaxel formulation Abraxane employs the most abundant plasma protein albumin as a delivery vehicle. The details of its advantages and disadvantages have been discussed in the previous sections. Lipoproteins including native and synthetic LDL and HDL (high-density lipoprotein) have been used for taxane delivery.[192-194] As endogenous carriers for lipids, lipoproteins have high biocompatibility, relatively long circulation half-life and functional capacity to deliver hydrophobic drugs.[195] LDL and HLD also have intrinsic targeting properties to LDL or HDL receptors which are overexpressed in various malignant cells and tumors.[196, 197] Enhanced targeting can also be obtained by conjugating targeting ligands.[198] However, native paclitaxel-LDL complexes were proven to be unstable in the presence of human plasma.[194] More importantly, the availability of lipoproteins is limited because of the difficulty in isolating native LDL/HDL or isolating apolipoproteins for the reconstitution of synthetic lipoproteins. As a result, production scale-up is challenging and cost is too high. The lipoprotein delivery system is still in their early development phase. Important safety issues such as immunogenicity have not been systematically investigated. Alternatively, the LDLmimicking nano-emulsions without the protein component or using peptides replacing the binding function of apolipoprotein B-100 were developed.[115, 119] These lipid-based nanoparticles can be viewed as an evolution of lipoprotein-based formulations.

In addition to these major types of nanoparticles, there are other minor classes of nanoparticles designed and investigated for the delivery of taxanes as well. One of the examples is inorganic nanoparticles including silica nanoparticle, gold nanoparticles, magnetic nanoparticle, and quantum dots, as well as others.[199] The surface of these nanoparticles is usually physically or chemically modified or functionalized. Except for porous silica nanoparticles which incorporate hydrophobic drug into their interior pores, most of the inorganic nanoparticles covalently conjugate taxane to their functionalized surface.[200-204] Besides their small, uniform and tunable particle sizes, another major advantage of these nanoparticles is their multi-functionality. The gold nanoparticles, magnetic nanoparticles, and quantum dots are capable of delivering anticancer agents with simultaneous optical imaging and localization of tumors. An obvious drawback of these inorganic nanoparticles is their relatively low biocompatibility as compared to lipid-based nanoparticles. Researchers are working on the improvement of their biocompatibility by approaches like modifying the nanoparticles with a lipid coating.[205] 


\section{Future perspective}

It has been demonstrated by clinical oncologists that to achieve the maximal anticancer effect, therapies that hit as many potential targets or pathways as possible are desirable because cancer cells are a population of highly heterogeneous cells. Hence, a delivery system capable of delivering combination of multiple anticancer agents, such as cytotoxic drugs, drugs targeting specific biomarkers, radiotherapeutics, vaccines, and even siRNA, is the future direction that researchers should pursue. Diagnostic probes can also be incorporated either on the surface or entrapped in the nanoparticles to achieve multiple functions. Co-delivery of anticancer agents and highly sensitive diagnostic probe enables an early detection of drug response or resistance and an early evaluation of benefit/risk ratio of current therapy which makes prompt regimen adjustment and individualized medication possible.

Identifying novel targets and ligands with more specificity relies on the advances in molecular biology and would benefit active taxane targeting delivery. For example, the evolution of antibody-type ligand apparently brings benefits to active targeting. The early development of antibodies derived from animals led to targeting ligands that were highly immunogenic in humans. Later, chimeric antibodies, completely humanized antibodies, Fab ', and single chain variable fragment were developed so that not only the issue of immunogenicity is substantially reduced, but also the size of ligand was significantly smaller which favors nano-based formulations as a whole. More recently, a new generation of binding ligands such as monobodies, affibodies, heptameric binding domains have been developed for basic research while at the same time attracts increasing interests for the application in active pharmaceutical delivery due to their high binding affinity and potentially low immunogenicity. Moreover, identifying more specifically expressed target such as receptors, integrins and enzymes in pathological tissues is also going to facilitate the development of active targeted therapeutics with more specificity.

To date, parenteral infusion of taxanes is the only administration route used in the clinic. The development of oral dosage form for taxanes is impeded by their toxicity to rapidproliferating intestinal epithelium. Although several studies have demonstrated enhanced bioavailability of taxanes facilitated by lipid-based nano-based formulations, a great deal of effort is still needed to minimize the drug-associated GI toxicity as well as carrier-associated toxicity before oral taxane administration becomes feasible.

Environmentally responsive drug delivery systems in response to temperature, $\mathrm{pH}$, ionic strength, enzyme, or oxidative/reductive environment offer great advantages in drug delivery. The unique physiology of solid tumors such as slightly acidic $\mathrm{pH}$, hypoxia in most solid tumors, and overexpression of some enzymes (e.g., sialidase, matrix metalloproteinase) provide great opportunity for the design of environmentally responsive drug delivery systems to specifically release taxanes in tumor site. However, these types of "smart" delivery systems mainly take advantage of unique physic-chemical properties of polymeric materials. Since many lipid-based delivery systems such as nanocapsules and core/shell nanoparticles are hybrid of lipid and polymeric carriers, the idea of environmentally responsive delivery also has the potential to be integrated to lipid-based nano-delivery systems. Alternatively, taxanes themselves can be modified to prodrugs with environmentally responsive linkers.

Nano-based formulations may offer attractive solutions for the safe and effective delivery of taxanes. However, there are still noticeable gaps to fill before the theoretical advantage of these formulations may truly be realized. 


\section{References}

1. Cortes JE, Pazdur R. Docetaxel. J Clin Oncol. 1995; 13:2643-2655. [PubMed: 7595719]

2. Hamada H, Ishihara K, Masuoka N, Mikuni K, Nakajima N. Enhancement of water-solubility and bioactivity of paclitaxel using modified cyclodextrins. J Biosci Bioeng. 2006; 102:369-371. [PubMed: 17116587]

3. Mathew AE, Mejillano MR, Nath JP, Himes RH, Stella VJ. Synthesis and Evaluation of Some Water-Soluble Prodrugs and Derivatives of Taxol with Antitumor-Activity. J Med Chem. 1992; 35:145-151. [PubMed: 1346275]

4. Du W, Hong L, Yao T, Yang X, He Q, Yang B, Hu Y. Synthesis and evaluation of water-soluble docetaxel prodrugs-docetaxel esters of malic acid. Bioorg Med Chem. 2007; 15:6323-6330. [PubMed: 17624790]

5. Ali SM, Hoemann MZ, Aube J, Georg GI, Mitscher LA, Jayasinghe LR. Butitaxel analogues: synthesis and structure-activity relationships. J Med Chem. 1997; 40:236-241. [PubMed: 9003522]

6. Zaske L, Perrin MA, Leveiller F. Docetaxel: Solid state characterization by X-ray powder diffraction and thermogravimetry. J Phys Iv. 2001; 11:221-226.

7. Schiff PB, Fant J, Horwitz SB. Promotion of microtubule assembly in vitro by taxol. Nature. 1979; 277:665-667. [PubMed: 423966]

8. Ringel I, Horwitz SB. Studies with RP 56976 (taxotere): a semisynthetic analogue of taxol. J Natl Cancer Inst. 1991; 83:288-291. [PubMed: 1671606]

9. Horwitz SB. Mechanism of action of taxol. Trends Pharmacol Sci. 1992; 13:134-136. [PubMed: 1350385]

10. Guerittevoegelein F, Guenard D, Lavelle F, Legoff MT, Mangatal L, Potier P. Relationships between the Structure of Taxol Analogs and Their Antimitotic Activity. J Med Chem. 1991; 34:992-998. [PubMed: 1672159]

11. Diaz JF, Andreu JM. Assembly of Purified Gdp Tubulin into Microtubules Induced by Taxol and Taxotere - Reversibility, Ligand Stoichiometry, and Competition. Biochemistry-Us. 1993; 32:2747-2755.

12. Riou J, Petitgenet O, Combeau C, et al. Cellular uptake and efflux of docetaxel (Taxotere) and paclitaxel (Taxol) in P388 cell line. Proc Am Ass Cancer Res. 1994; 35:385.

13. Taxol $^{\circledR}$ (paclitaxel) Injection. Bristol-Myers Squibb; Princeton: 2011.

14. Sonnichsen DS, Relling MV. Clinical pharmacokinetics of paclitaxel. Clin Pharmacokinet. 1994; 27:256-269. [PubMed: 7834963]

15. Rowinsky EK, Wright M, Monsarrat B, Donehower RC. Clinical pharmacology and metabolism of Taxol (paclitaxel): update 1993. Ann Oncol. 1994; 5(Suppl 6):S7-16. [PubMed: 7865438]

16. Ellis AG, Crinis NA, Webster LK. Inhibition of etoposide elimination in the isolated perfused rat liver by Cremophor EL and Tween 80. Cancer Chemoth Pharm. 1996; 38:81-87.

17. Sparreboom A, van Zuylen L, Brouwer E, Loos WJ, de Bruijn P, Gelderblom H, Pillay M, Nooter K, Stoter G, Verweij J. Cremophor EL-mediated alteration of paclitaxel distribution in human blood: clinical pharmacokinetic implications. Cancer Res. 1999; 59:1454-1457. [PubMed: 10197613]

18. van Zuylen L, Karlsson MO, Verweij J, Brouwer E, de Bruijn P, Nooter K, Stoter G, Sparreboom A. Pharmacokinetic modeling of paclitaxel encapsulation in Cremophor EL micelles. Cancer Chemother Pharmacol. 2001; 47:309-318. [PubMed: 11345647]

19. Weiss RB, Donehower RC, Wiernik PH, Ohnuma T, Gralla RJ, Trump DL, Baker JR Jr, Van Echo DA, Von Hoff DD, Leyland-Jones B. Hypersensitivity reactions from taxol. J Clin Oncol. 1990; 8:1263-1268. [PubMed: 1972736]

20. Ibrahim NK, Desai N, Legha S, Soon-Shiong P, Theriault RL, Rivera E, Esmaeli B, Ring SE, Bedikian A, Hortobagyi GN, Ellerhorst JA. Phase I and pharmacokinetic study of ABI-007, a Cremophor-free, protein-stabilized, nanoparticle formulation of paclitaxel. Clin Cancer Res. 2002; 8:1038-1044. [PubMed: 12006516]

21. Gradishar WJ. Albumin-bound paclitaxel: a next-generation taxane. Expert Opin Pharmacother. 2006; 7:1041-1053. [PubMed: 16722814] 
22. Loos WJ, Baker SD, Verweij J, Boonstra JG, Sparreboom A. Clinical pharmacokinetics of unbound docetaxel: role of polysorbate 80 and serum proteins. Clin Pharmacol Ther. 2003; 74:364-371. [PubMed: 14534523]

23. Bissery M, Renard A, Andre S, et al. Preclinical pharmacology and toxicology of Taxotere (RP 56976, NSC 628503). Ann Oncol. 1992; 3:121.

24. Bissery MCRA, Montay G, et al. Taxotere: Antitumor activity and pharmacokinetics in mice. Proc Am Ass Cancer Res. 1991; 32:401.

25. Pinguet F, Agustin MJ, Brown P, Soefje S, Needleman R, Sanchez MN, Sommer U, Tranter B. New formulation Taxotere $(\mathrm{R})$ reduces preparation time and supports the physical stability of the product in infusion bags: data from the RELIUS international observational study. Ejhp Pract. 2010; 16:40-43.

26. Marupudi NI, Han JE, Li KW, Renard VM, Tyler BM, Brem H. Paclitaxel: a review of adverse toxicities and novel delivery strategies. Expert Opin Drug Saf. 2007; 6:609-621. [PubMed: 17877447]

27. Rowinsky EK. The development and clinical utility of the taxane class of antimicrotubule chemotherapy agents. Annu Rev Med. 1997; 48:353-374. [PubMed: 9046968]

28. Campbell RB. Tumor physiology and delivery of nanopharmaceuticals. Anticancer Agents Med Chem. 2006; 6:503-512. [PubMed: 17100555]

29. Jain RK, Stylianopoulos T. Delivering nanomedicine to solid tumors. Nat Rev Clin Oncol. 2010; 7:653-664. [PubMed: 20838415]

30. Shubik P. Vascularization of tumors: a review. J Cancer Res Clin Oncol. 1982; 103:211-226. [PubMed: 6181069]

31. Hobbs SK, Monsky WL, Yuan F, Roberts WG, Griffith L, Torchilin VP, Jain RK. Regulation of transport pathways in tumor vessels: role of tumor type and microenvironment. Proc Natl Acad Sci U S A. 1998; 95:4607-4612. [PubMed: 9539785]

32. Takakura Y, Mahato RI, Hashida M. Extravasation of macromolecules. Adv Drug Deliv Rev. 1998; 34:93-108. [PubMed: 10837672]

33. Karakotchian M, Fraser IS. An ultrastructural study of microvascular inter-endothelial tight junctions in normal endometrium. Micron. 2007; 38:632-636. [PubMed: 17101273]

34. Hashizume H, Baluk P, Morikawa S, McLean JW, Thurston G, Roberge S, Jain RK, McDonald DM. Openings between defective endothelial cells explain tumor vessel leakiness. Am J Pathol. 2000; 156:1363-1380. [PubMed: 10751361]

35. Leu AJ, Berk DA, Lymboussaki A, Alitalo K, Jain RK. Absence of functional lymphatics within a murine sarcoma: A molecular and functional evaluation. Cancer Research. 2000; 60:4324-4327. [PubMed: 10969769]

36. Padera TP, Stoll BR, Tooredman JB, Capen D, di Tomaso E, Jain RK. Pathology: cancer cells compress intratumour vessels. Nature. 2004; 427:695. [PubMed: 14973470]

37. Maeda H, Wu J, Sawa T, Matsumura Y, Hori K. Tumor vascular permeability and the EPR effect in macromolecular therapeutics: a review. J Control Release. 2000; 65:271-284. [PubMed: 10699287]

38. Boucher Y, Kirkwood JM, Opacic D, Desantis M, Jain RK. Interstitial hypertension in superficial metastatic melanomas in humans. Cancer Res. 1991; 51:6691-6694. [PubMed: 1742743]

39. Sevick EM, Jain RK. Geometric resistance to blood flow in solid tumors perfused ex vivo: effects of tumor size and perfusion pressure. Cancer Res. 1989; 49:3506-3512. [PubMed: 2731172]

40. Vijayagopal P, Figueroa JE, Levine EA. Altered composition and increased endothelial cell proliferative activity of proteoglycans isolated from breast carcinoma. J Surg Oncol. 1998; 68:250-254. [PubMed: 9721712]

41. Pluen A, Boucher Y, Ramanujan S, McKee TD, Gohongi T, di Tomaso E, Brown EB, Izumi Y, Campbell RB, Berk DA, Jain RK. Role of tumor-host interactions in interstitial diffusion of macromolecules: cranial vs. subcutaneous tumors. Proc Natl Acad Sci U S A. 2001; 98:46284633. [PubMed: 11274375]

42. Chauhan VP, Lanning RM, Diop-Frimpong B, Mok W, Brown EB, Padera TP, Boucher Y, Jain RK. Multiscale measurements distinguish cellular and interstitial hindrances to diffusion in vivo. Biophys J. 2009; 97:330-336. [PubMed: 19580771] 
43. Alexandrakis G, Brown EB, Tong RT, McKee TD, Campbell RB, Boucher Y, Jain RK. Twophoton fluorescence correlation microscopy reveals the two-phase nature of transport in tumors. Nat Med. 2004; 10:203-207. [PubMed: 14716306]

44. Voskoglou-Nomikos T, Pater JL, Seymour L. Clinical predictive value of the in vitro cell line, human xenograft, and mouse allograft preclinical cancer models. Clin Cancer Res. 2003; 9:42274239. [PubMed: 14519650]

45. Dong X, Mattingly CA, Tseng MT, Cho MJ, Liu Y, Adams VR, Mumper RJ. Doxorubicin and paclitaxel-loaded lipid-based nanoparticles overcome multidrug resistance by inhibiting Pglycoprotein and depleting ATP. Cancer Res. 2009; 69:3918-3926. [PubMed: 19383919]

46. Sharma SV, Haber DA, Settleman J. Cell line-based platforms to evaluate the therapeutic efficacy of candidate anticancer agents. Nat Rev Cancer. 2010; 10:241-253. [PubMed: 20300105]

47. Kerbel RS. Human tumor xenografts as predictive preclinical models for anticancer drug activity in humans - Better than commonly perceived - But they can be improved. Cancer Biol Ther. 2003; 2:S134-S139. [PubMed: 14508091]

48. Peterson JK, Houghton PJ. Integrating pharmacology and in vivo cancer models in preclinical and clinical drug development. Eur J Cancer. 2004; 40:837-844. [PubMed: 15120039]

49. Takimoto CH. Why drugs fail: of mice and men revisited. Clin Cancer Res. 2001; 7:229-230. [PubMed: 11234873]

50. Suggitt M, Bibby MC. 50 years of preclinical anticancer drug screening: empirical to target-driven approaches. Clin Cancer Res. 2005; 11:971-981. [PubMed: 15709162]

51. Naito S, von Eschenbach AC, Fidler IJ. Different growth pattern and biologic behavior of human renal cell carcinoma implanted into different organs of nude mice. J Natl Cancer Inst. 1987; 78:377-385. [PubMed: 3468299]

52. Morikawa K, Walker SM, Jessup JM, Fidler IJ. In vivo selection of highly metastatic cells from surgical specimens of different primary human colon carcinomas implanted into nude mice. Cancer Res. 1988; 48:1943-1948. [PubMed: 3349467]

53. Gohji K, Nakajima M, Fabra A, Bucana CD, von Eschenbach AC, Tsuruo T, Fidler IJ. Regulation of gelatinase production in metastatic renal cell carcinoma by organ-specific fibroblasts. Jpn J Cancer Res. 1994; 85:152-160. [PubMed: 8144397]

54. Gutman M, Singh RK, Price JE, Fan D, Fidler IJ. Accelerated growth of human colon cancer cells in nude mice undergoing liver regeneration. Invasion Metastasis. 1994; 14:362-371. [PubMed: 7657529]

55. Killion JJ, Radinsky R, Fidler IJ. Orthotopic models are necessary to predict therapy of transplantable tumors in mice. Cancer Metastasis Rev. 1998; 17:279-284. [PubMed: 10352881]

56. Schuetz JD, Schuetz EG. Extracellular matrix regulation of multidrug resistance in primary monolayer cultures of adult rat hepatocytes. Cell Growth Differ. 1993; 4:31-40. [PubMed: 8424904]

57. Mead JE, Fausto N. Transforming Growth Factor-Alpha May Be a Physiological Regulator of Liver-Regeneration by Means of an Autocrine Mechanism. P Natl Acad Sci USA. 1989; 86:15581562.

58. Hoffman RM. Green fluorescent protein imaging of tumour growth, metastasis, and angiogenesis in mouse models. Lancet Oncol. 2002; 3:546-556. [PubMed: 12217792]

59. El Hilali N, Rubio N, Martinez-Villacampa M, Blanco J. Combined noninvasive imaging and luminometric quantification of luciferase-labeled human prostate tumors and metastases. Lab Invest. 2002; 82:1563-1571. [PubMed: 12429816]

60. Kuo TH, Kubota T, Watanabe M, Furukawa T, Kase S, Tanino H, Saikawa Y, Ishibiki K, Kitajima M, Hoffman RM. Site-Specific Chemosensitivity of Human Small-Cell Lung-Carcinoma Growing Orthotopically Compared to Subcutaneously in Scid Mice - the Importance of Orthotopic Models to Obtain Relevant Drug-Evaluation Data. Anticancer Res. 1993; 13:627-630. [PubMed: 8391244]

61. Fidler IJ, Ellis LM. The implications of angiogenesis for the biology and therapy of cancer metastasis. Cell. 1994; 79:185-188. [PubMed: 7525076] 
62. Cowen SE, Bibby MC, Double JA. Characterization of the Vasculature within a Murine Adenocarcinoma Growing in Different Sites to Evaluate the Potential of Vascular Therapies. Acta Oncol. 1995; 34:357-360. [PubMed: 7779423]

63. Wilmanns C, Fan D, Obrian C, Radinsky R, Bucana C, Tsan R, Fidler I. Modulation of Doxorubicin sensitivity and level of p-glycoprotein expression in human colon-carcinoma cells by ectopic and orthotopic environments in nude-mice. Int J Oncol. 1993; 3:413-422. [PubMed: 21573380]

64. Dexter DL, Diamond M, Creveling J, Chen SF. Chemotherapy of Mammary Carcinomas Arising in Ras Transgenic Mice. Invest New Drug. 1993; 11:161-168.

65. Rego EM, He LZ, Warrell RP Jr, Wang ZG, Pandolfi PP. Retinoic acid (RA) and As2O3 treatment in transgenic models of acute promyelocytic leukemia (APL) unravel the distinct nature of the leukemogenic process induced by the PML-RARalpha and PLZF-RARalpha oncoproteins. Proc Natl Acad Sci U S A. 2000; 97:10173-10178. [PubMed: 10954752]

66. Bearss DJ, Subler MA, Hundley JE, Troyer DA, Salinas RA, Windle JJ. Genetic determinants of response to chemotherapy in transgenic mouse mammary and salivary tumors. Oncogene. 2000; 19:1114-1122. [PubMed: 10713698]

67. Simeonova M, Ilarionova M, Ivanova T, Konstantinov C, Todorov D. Nanoparticles as drug carriers for vinblastine. Acute toxicity of vinblastine in a free form and associated to polybutylcyanoacrylate nanoparticles. Acta Physiol Pharmacol Bulg. 1991; 17:43-49. [PubMed: 1841517]

68. Souza LG, Silva EJ, Martins AL, Mota MF, Braga RC, Lima EM, Valadares MC, Taveira SF, Marreto RN. Development of topotecan loaded lipid nanoparticles for chemical stabilization and prolonged release. Eur J Pharm Biopharm. 2011; 79:189-196. [PubMed: 21352915]

69. Yang SC, Zhu JB. Preparation and characterization of camptothecin solid lipid nanoparticles. Drug Dev Ind Pharm. 2002; 28:265-274. [PubMed: 12026219]

70. Lim SJ, Lee MK, Kim CK. Altered chemical and biological activities of all-trans retinoic acid incorporated in solid lipid nanoparticle powders. J Control Release. 2004; 100:53-61. [PubMed: 15491810]

71. Williams J, Lansdown R, Sweitzer R, Romanowski M, LaBell R, Ramaswami R, Unger E. Nanoparticle drug delivery system for intravenous delivery of topoisomerase inhibitors. J Control Release. 2003; 91:167-172. [PubMed: 12932648]

72. Isacchi B, Arrigucci S, Marca GL, Bergonzi MC, Vannucchi MG, Novelli A, Bilia AR. Conventional and long-circulating liposomes of artemisinin: preparation, characterization, and pharmacokinetic profile in mice. J Liposome Res. 2010

73. Cole AJ, David AE, Wang J, Galban CJ, Hill HL, Yang VC. Polyethylene glycol modified, crosslinked starch-coated iron oxide nanoparticles for enhanced magnetic tumor targeting. Biomaterials. 2011; 32:2183-2193. [PubMed: 21176955]

74. Kim CK, Kim JY, Kim JK, Park JS, Byun Y. The use of PEGylated liposomes to prolong circulation lifetimes of tissue plasminogen activator. Biomaterials. 2009; 30:5751-5756. [PubMed: 19656559]

75. Immordino ML, Dosio F, Cattel L. Stealth liposomes: review of the basic science, rationale, and clinical applications, existing and potential. Int J Nanomedicine. 2006; 1:297-315. [PubMed: 17717971]

76. Benhabbour SRLJ, Kim D, Jain A, Wadhwa S, Parrott MC, Liu R, Desimone J, Mumper RJ. In vitro and in vivo assessment of targeting lipid-based nanoparticles to the epidermal growth factorreceptor (EGFR) using a novel Heptameric Z(EGFR) domain. J Control Release. 2011

77. Patel JD, O'Carra R, Jones J, Woodward JG, Mumper RJ. Preparation and characterization of nickel nanoparticles for binding to his-tag proteins and antigens. Pharm Res. 2007; 24:343-352. [PubMed: 17180725]

78. Cui Z, Patel J, Tuzova M, Ray P, Phillips R, Woodward JG, Nath A, Mumper RJ. Strong T cell type-1 immune responses to HIV-1 Tat (1-72) protein-coated nanoparticles. Vaccine. 2004; 22:2631-2640. [PubMed: 15193389] 
79. McConathy WJ, Nair MP, Paranjape S, Mooberry L, Lacko AG. Evaluation of synthetic/ reconstituted high-density lipoproteins as delivery vehicles for paclitaxel. Anti-Cancer Drug. 2008; 19:183-188.

80. Straubinger RM, Balasubramanian SV. Preparation and characterization of taxane-containing liposomes. Methods Enzymol. 2005; 391:97-117. [PubMed: 15721376]

81. Sharma A, Straubinger RM. Novel taxol formulations: preparation and characterization of taxolcontaining liposomes. Pharm Res. 1994; 11:889-896. [PubMed: 7937531]

82. Campbell RB, Balasubramanian SV, Straubinger RM. Influence of cationic lipids on the stability and membrane properties of paclitaxel-containing liposomes. J Pharm Sci. 2001; 90:1091-1105. [PubMed: 11536214]

83. Sharma A, Mayhew E, Straubinger RM. Antitumor effect of taxol-containing liposomes in a taxolresistant murine tumor model. Cancer Res. 1993; 53:5877-5881. [PubMed: 7903197]

84. Zhang JA, Anyarambhatla G, Ma L, Ugwu S, Xuan T, Sardone T, Ahmad I. Development and characterization of a novel Cremophor EL free liposome-based paclitaxel (LEP-ETU) formulation. Eur J Pharm Biopharm. 2005; 59:177-187. [PubMed: 15567316]

85. Balasubramanian SV, Alderfer JL, Straubinger RM. Solvent- and concentration-dependent molecular interactions of taxol (Paclitaxel). J Pharm Sci. 1994; 83:1470-1476. [PubMed: 7884672]

86. Balasubramanian SV, Straubinger RM. Taxol-lipid interactions: taxol-dependent effects on the physical properties of model membranes. Biochemistry-Us. 1994; 33:8941-8947.

87. Crosasso P, Ceruti M, Brusa P, Arpicco S, Dosio F, Cattel L. Preparation, characterization and properties of sterically stabilized paclitaxel-containing liposomes. J Control Release. 2000; 63:1930. [PubMed: 10640577]

88. Ishida T, Ichihara M, Wang X, Kiwada H. Spleen plays an important role in the induction of accelerated blood clearance of PEGylated liposomes. J Control Release. 2006; 115:243-250. [PubMed: 17011060]

89. Sharma A, Mayhew E, Bolcsak L, Cavanaugh C, Harmon P, Janoff A, Bernacki RJ. Activity of paclitaxel liposome formulations against human ovarian tumor xenografts. Int J Cancer. 1997; 71:103-107. [PubMed: 9096672]

90. Sharma A, Sharma US, Straubinger RM. Paclitaxel-liposomes for intracavitary therapy of intraperitoneal P388 leukemia. Cancer Lett. 1996; 107:265-272. [PubMed: 8947523]

91. Cabanes A, Briggs KE, Gokhale PC, Treat JA, Rahman A. Comparative in vivo studies with paclitaxel and liposome-encapsulated paclitaxel. Int J Oncol. 1998; 12:1035-1040. [PubMed: 9538125]

92. Schmitt-Sody M, Strieth S, Krasnici S, Sauer B, Schulze B, Teifel M, Michaelis U, Naujoks K, Dellian M. Neovascular targeting therapy: paclitaxel encapsulated in cationic liposomes improves antitumoral efficacy. Clin Cancer Res. 2003; 9:2335-2341. [PubMed: 12796403]

93. Soepenberg O, Sparreboom A, de Jonge MJ, Planting AS, de Heus G, Loos WJ, Hartman CM, Bowden C, Verweij J. Real-time pharmacokinetics guiding clinical decisions; phase I study of a weekly schedule of liposome encapsulated paclitaxel in patients with solid tumours. Eur J Cancer. 2004; 40:681-688. [PubMed: 15010068]

94. Arleth L, Ashok B, Onyuksel H, Thiyagarajan P, Jacob J, Hjelm RP. Detailed structure of hairy mixed micelles formed by phosphatidylcholine and PEGylated phospholipids in aqueous media. Langmuir. 2005; 21:3279-3290. [PubMed: 15807565]

95. Mu L, Elbayoumi TA, Torchilin VP. Mixed micelles made of poly(ethylene glycol)phosphatidylethanolamine conjugate and D-alpha-tocopheryl polyethylene glycol 1000 succinate as pharmaceutical nanocarriers for camptothecin. Int J Pharmaceut. 2005; 306:142-149.

96. Vakil R, Kwon GS. Effect of cholesterol on the release of amphotericin B from PEG-phospholipid micelles. Mol Pharm. 2008; 5:98-104. [PubMed: 18159926]

97. Ashok B, Arleth L, Hjelm RP, Rubinstein I, Onyuksel H. In vitro characterization of PEGylated phospholipid micelles for improved drug solubilization: effects of PEG chain length and PC incorporation. J Pharm Sci. 2004; 93:2476-2487. [PubMed: 15349957] 
98. Lim SB, Rubinstein I, Onyuksel H. Freeze drying of peptide drugs self-associated with longcirculating, biocompatible and biodegradable sterically stabilized phospholipid nanomicelles. Int J Pharm. 2008; 356:345-350. [PubMed: 18289811]

99. La SB, Okano T, Kataoka K. Preparation and characterization of the micelle-forming polymeric drug indomethacin-incorporated poly(ethylene oxide)-poly(beta-benzyl L-aspartate) block copolymer micelles. J Pharm Sci. 1996; 85:85-90. [PubMed: 8926590]

100. Krishnadas A, Rubinstein I, Onyuksel H. Sterically stabilized phospholipid mixed micelles: in vitro evaluation as a novel carrier for water-insoluble drugs. Pharm Res. 2003; 20:297-302. [PubMed: 12636171]

101. Onyuksel H, Jeon E, Rubinstein I. Nanomicellar paclitaxel increases cytotoxicity of multidrug resistant breast cancer cells. Cancer Lett. 2009; 274:327-330. [PubMed: 19022562]

102. Dabholkar RD, Sawant RM, Mongayt DA, Devarajan PV, Torchilin VP. Polyethylene glycolphosphatidylethanolamine conjugate (PEG-PE)-based mixed micelles: some properties, loading with paclitaxel, and modulation of P-glycoprotein-mediated efflux. Int J Pharm. 2006; 315:148157. [PubMed: 16616818]

103. Sawant RR, Torchilin VP. Multifunctionality of lipid-core micelles for drug delivery and tumour targeting. Mol Membr Biol. 2010; 27:232-246. [PubMed: 20929339]

104. Lukyanov AN, Gao Z, Mazzola L, Torchilin VP. Polyethylene glycol-diacyllipid micelles demonstrate increased acculumation in subcutaneous tumors in mice. Pharm Res. 2002; 19:1424-1429. [PubMed: 12425458]

105. Anton N, Vandamme TF. Nano-emulsions and micro-emulsions: clarifications of the critical differences. Pharm Res. 2011; 28:978-985. [PubMed: 21057856]

106. Lawrence MJ, Rees GD. Microemulsion-based media as novel drug delivery systems. Adv Drug Deliver Rev. 2000; 45:89-121.

107. Solans PIC, Nolla J, Azemar N, Garcia-Celma MJ. Nano-emulsions. Current Opinion in Colloid \& Interface Science. 2005; 10:102-110.

108. Tarr BD, Sambandan TG, Yalkowsky SH. A new parenteral emulsion for the administration of taxol. Pharm Res. 1987; 4:162-165. [PubMed: 2908138]

109. Constantinides PP, Lambert KJ, Tustian AK, Schneider B, Lalji S, Ma W, Wentzel B, Kessler D, Worah D, Quay SC. Formulation development and antitumor activity of a filter-sterilizable emulsion of paclitaxel. Pharm Res. 2000; 17:175-182. [PubMed: 10751032]

110. Constantinides PP, Tustian A, Kessler DR. Tocol emulsions for drug solubilization and parenteral delivery. Adv Drug Deliv Rev. 2004; 56:1243-1255. [PubMed: 15109767]

111. Gao JSK, Liu K, Liu XH, He ZG. Preparation and Characterization of a Submicron lipid Emulsion of Docetaxel: Submicron Lipid Emulsion of Docetaxel. Drug Dev Ind Pharm. 2008; 34:1227-1237. [PubMed: 18720137]

112. Kan P, Chen ZB, Lee CJ, Chu IM. Development of nonionic surfactant/phospholipid o/w emulsion as a paclitaxel delivery system. J Control Release. 1999; 58:271-278. [PubMed: 10099152]

113. Tiwari SB, Amiji MM. Improved oral delivery of paclitaxel following administration in nanoemulsion formulations. J Nanosci Nanotechnol. 2006; 6:3215-3221. [PubMed: 17048539]

114. Yin YM, Cui FD, Mu CF, Choi MK, Kim JS, Chung SJ, Shim CK, Kim DD. Docetaxel microemulsion for enhanced oral bioavailability: preparation and in vitro and in vivo evaluation. J Control Release. 2009; 140:86-94. [PubMed: 19709639]

115. Maranhao RC, Garicochea B, Silva EL, Dorlhiac-Llacer P, Cadena SM, Coelho IJ, Meneghetti JC, Pileggi FJ, Chamone DA. Plasma kinetics and biodistribution of a lipid emulsion resembling low-density lipoprotein in patients with acute leukemia. Cancer Res. 1994; 54:4660-4666. [PubMed: 8062260]

116. Rodrigues DG, Maria DA, Fernandes DC, Valduga CJ, Couto RD, Ibanez OC, Maranhao RC. Improvement of paclitaxel therapeutic index by derivatization and association to a cholesterolrich microemulsion: in vitro and in vivo studies. Cancer Chemother Pharmacol. 2005; 55:565576. [PubMed: 15726368]

117. Dias ML, Carvalho JP, Rodrigues DG, Graziani SR, Maranhao RC. Pharmacokinetics and tumor uptake of a derivatized form of paclitaxel associated to a cholesterol-rich nanoemulsion (LDE) in 
patients with gynecologic cancers. Cancer Chemother Pharmacol. 2007; 59:105-111. [PubMed: 16699792]

118. Pires L, Hegg R, Valduga C, Graziani S, Rodrigues D, Maranhao RC. Use of cholesterol-rich nanoparticles that bind to lipoprotein receptors as a vehicle to paclitaxel in the treatment of breast cancer: pharmacokinetics, tumor uptake and a pilot clinical study. Cancer Chemoth Pharm. 2009; 63:281-287.

119. Nikanjarn M, Gibbs AR, Hunt A, Budinger TF, Forte TM. Synthetic nano-LDL with paclitaxel oleate as a targeted drug delivery vehicle for glioblastoma multiforme. Journal of Controlled Release. 2007; 124:163-171. [PubMed: 17964677]

120. Wissing SA, Kayser O, Muller RH. Solid lipid nanoparticles for parenteral drug delivery. Adv Drug Deliv Rev. 2004; 56:1257-1272. [PubMed: 15109768]

121. Muller RH, Mader K, Gohla S. Solid lipid nanoparticles (SLN) for controlled drug delivery - a review of the state of the art. Eur J Pharm Biopharm. 2000; 50:161-177. [PubMed: 10840199]

122. Jenning V, Lippacher A, Gohla SH. Medium scale production of solid lipid nanoparticles (SLN) by high pressure homogenization. J Microencapsul. 2002; 19:1-10. [PubMed: 11811751]

123. Dingler A, Gohla S. Production of solid lipid nanoparticles (SLN): scaling up feasibilities. J Microencapsul. 2002; 19:11-16. [PubMed: 11811752]

124. Oyewumi MO, Mumper RJ. Gadolinium-loaded nanoparticles engineered from microemulsion templates. Drug Dev Ind Pharm. 2002; 28:317-328. [PubMed: 12026224]

125. Chen DB, Yang TZ, Lu WL, Zhang Q. In vitro and in vivo study of two types of long-circulating solid lipid nanoparticles containing paclitaxel. Chem Pharm Bull (Tokyo). 2001; 49:1444-1447. [PubMed: 11724235]

126. Lee MK, Lim SJ, Kim CK. Preparation, characterization and in vitro cytotoxicity of paclitaxelloaded sterically stabilized solid lipid nanoparticles. Biomaterials. 2007; 28:2137-2146. [PubMed: 17257668]

127. Dong XW, Mattingly CA, Tseng M, Cho M, Adams VR, Mumper RJ. Development of new lipidbased paclitaxel nanoparticles using sequential simplex optimization. European Journal of Pharmaceutics and Biopharmaceutics. 2009; 72:9-17. [PubMed: 19111929]

128. Shenoy VS, Rajyaguru TH, Gude RP, Murthy RS. Studies on paclitaxel-loaded glyceryl monostearate nanoparticles. J Microencapsul. 2009; 26:471-478. [PubMed: 19169921]

129. Cavalli R, Caputo O, Gasco MR. Preparation and characterization of solid lipid nanospheres containing paclitaxel. Eur J Pharm Sci. 2000; 10:305-309. [PubMed: 10838020]

130. Shahgaldian P, Da Silva E, Coleman AW, Rather B, Zaworotko MJ. Para-acyl-calix-arene based solid lipid nanoparticles (SLNs): a detailed study of preparation and stability parameters. Int J Pharm. 2003; 253:23-38. [PubMed: 12593934]

131. Westesen K, Bunjes H, Koch MHJ. Physicochemical characterization of lipid nanoparticles and evaluation of their drug loading capacity and sustained release potential. Journal of Controlled Release. 1997; 48:223-236.

132. Arica Yegin B, Benoit JP, Lamprecht A. Paclitaxel-loaded lipid nanoparticles prepared by solvent injection or ultrasound emulsification. Drug Dev Ind Pharm. 2006; 32:1089-1094. [PubMed: 17012121]

133. zur Muhlen A, Schwarz C, Mehnert W. Solid lipid nanoparticles (SLN) for controlled drug delivery--drug release and release mechanism. Eur J Pharm Biopharm. 1998; 45:149-155. [PubMed: 9704911]

134. Muhlen A, Mehnert W. Drug release and release mechanism of prednisolone loaded solid lipid nanoparticles. Pharmazie. 1998; 53:552.

135. Muller RH, Radtke M, Wissing SA. Nanostructured lipid matrices for improved microencapsulation of drugs. Int J Pharm. 2002; 242:121-128. [PubMed: 12176234]

136. Yuan H, Miao J, Du YZ, You J, Hu FQ, Zeng S. Cellular uptake of solid lipid nanoparticles and cytotoxicity of encapsulated paclitaxel in A549 cancer cells. Int J Pharm. 2008; 348:137-145. [PubMed: 17714896]

137. Koziara JM, Oh JJ, Akers WS, Ferraris SP, Mumper RJ. Blood compatibility of cetyl alcohol/ polysorbate-based nanoparticles. Pharm Res. 2005; 22:1821-1828. [PubMed: 16132346] 
138. Wang JX, Sun X, Zhang ZR. Enhanced brain targeting by synthesis of $3^{\prime}, 5^{\prime}$-dioctanoyl-5fluoro- $2^{\prime}$-deoxyuridine and incorporation into solid lipid nanoparticles. European Journal of Pharmaceutics and Biopharmaceutics. 2002; 54:285-290. [PubMed: 12445558]

139. Fundaro A, Cavalli R, Bargoni A, Vighetto D, Zara GP, Gasco MR. Non-stealth and stealth solid lipid nanoparticles (SLN) carrying doxorubicin: pharmacokinetics and tissue distribution after i.v. administration to rats. Pharmacol Res. 2000; 42:337-343. [PubMed: 10987994]

140. Zara GP, Cavalli R, Bargoni A, Fundaro A, Vighetto D, Gasco MR. Intravenous administration to rabbits of non-stealth and stealth doxorubicin-loaded solid lipid nanoparticles at increasing concentrations of stealth agent: pharmacokinetics and distribution of doxorubicin in brain and other tissues. J Drug Target. 2002; 10:327-335. [PubMed: 12164381]

141. Zara GP, Cavalli R, Fundaro A, Bargoni A, Caputo O, Gasco MR. Pharmacokinetics of doxorubicin incorporated in solid lipid nanospheres (SLN). Pharmacol Res. 1999; 40:281-286. [PubMed: 10479474]

142. Yang SC, Lu LF, Cai Y, Zhu JB, Liang BW, Yang CZ. Body distribution in mice of intravenously injected camptothecin solid lipid nanoparticles and targeting effect on brain. J Control Release. 1999; 59:299-307. [PubMed: 10332062]

143. Harivardhan Reddy L, Sharma RK, Chuttani K, Mishra AK, Murthy RS. Influence of administration route on tumor uptake and biodistribution of etoposide loaded solid lipid nanoparticles in Dalton's lymphoma tumor bearing mice. J Control Release. 2005; 105:185-198. [PubMed: 15921775]

144. Koziara JM, Lockman PR, Allen DD, Mumper RJ. Paclitaxel nanoparticles for the potential treatment of brain tumors. J Control Release. 2004; 99:259-269. [PubMed: 15380635]

145. Landfester K. Polyreactions in miniemulsions. Abstr Pap Am Chem S. 2002; 224:U500-U500.

146. Rollot JM, Couvreur P, Roblot-Treupel L, Puisieux F. Physicochemical and morphological characterization of polyisobutyl cyanoacrylate nanocapsules. J Pharm Sci. 1986; 75:361-364. [PubMed: 3723356]

147. Scott C, Wu D, Ho CC, Co CC. Liquid-core capsules via interfacial polymerization: a free-radical analogy of the nylon rope trick. J Am Chem Soc. 2005; 127:4160-4161. [PubMed: 15783184]

148. Galindo-Rodriguez S, Allemann E, Fessi H, Doelker E. Physicochemical parameters associated with nanoparticle formation in the salting-out, emulsification-diffusion, and nanoprecipitation methods. Pharm Res. 2004; 21:1428-1439. [PubMed: 15359578]

149. Bartoli MH, Boitard M, Fessi H, Beriel H, Devissaguet JP, Picot F, Puisieux F. In vitro and in vivo antitumoral activity of free, and encapsulated taxol. J Microencapsul. 1990; 7:191-197. [PubMed: 1970357]

150. Oh KS, Lee KE, Han SS, Cho SH, Kim D, Yuk SH. Formation of core/shell nanoparticles with a lipid core and their application as a drug delivery system. Biomacromolecules. 2005; 6:10621067. [PubMed: 15762679]

151. Bae KH, Lee Y, Park TG. Oil-encapsulating PEO-PPO-PEO/PEG shell cross-linked nanocapsules for target-specific delivery of paclitaxel. Biomacromolecules. 2007; 8:650-656. [PubMed: 17291088]

152. Zhang Y, Zhu SY, Yin LC, Qian F, Tang C, Yin CH. Preparation, characterization and biocompatibility of poly(ethylene glycol)-poly(n-butyl cyanoacrylate) nanocapsules with oil core via miniemulsion polymerization. Eur Polym J. 2008; 44:1654-1661.

153. Huynh NT, Passirani C, Saulnier P, Benoit JP. Lipid nanocapsules: A new platform for nanomedicine. Int J Pharmaceut. 2009; 379:201-209.

154. Heurtault B, Saulnier P, Pech B, Proust JE, Benoit JP. A novel phase inversion-based process for the preparation of lipid nanocarriers. Pharm Res. 2002; 19:875-880. [PubMed: 12134960]

155. Lacoeuille F, Hindre F, Moal F, Roux J, Passirani C, Couturier O, Cales P, Le Jeune JJ, Lamprecht A, Benoit JP. In vivo evaluation of lipid nanocapsules as a promising colloidal carrier for paclitaxel. Int J Pharmaceut. 2007; 344:143-149.

156. Garcion E, Lamprecht A, Heurtault B, Paillard A, Aubert-Pouessel A, Denizot B, Menei P, Benoit JP. A new generation of anticancer, drug-loaded, colloidal vectors reverses multidrug resistance in glioma and reduces tumor progression in rats. Mol Cancer Ther. 2006; 5:17101722. [PubMed: 16891457] 
157. Peltier S, Oger JM, Lagarce F, Couet W, Benoit JP. Enhanced oral paclitaxel bioavailability after administration of paclitaxel-loaded lipid nanocapsules. Pharm Res. 2006; 23:1243-1250. [PubMed: 16715372]

158. Khalid MN, Simard P, Hoarau D, Dragomir A, Leroux JC. Long circulating poly(ethylene glycol)-decorated lipid nanocapsules deliver docetaxel to solid tumors. Pharm Res. 2006; 23:752-758. [PubMed: 16550475]

159. Skwarczynski M, Hayashi Y, Kiso Y. Paclitaxel prodrugs: toward smarter delivery of anticancer agents. J Med Chem. 2006; 49:7253-7269. [PubMed: 17149855]

160. Stevens PJ, Sekido M, Lee RJ. A folate receptor-targeted lipid nanoparticle formulation for a lipophilic paclitaxel prodrug. Pharm Res. 2004; 21:2153-2157. [PubMed: 15648245]

161. Lundberg BB, Risovic V, Ramaswamy M, Wasan KM. A lipophilic paclitaxel derivative incorporated in a lipid emulsion for parenteral administration. J Control Release. 2003; 86:93100. [PubMed: 12490375]

162. Huynh L, Leroux JC, Allen C. Enhancement of docetaxel solubility via conjugation of formulation-compatible moieties. Org Biomol Chem. 2009; 7:3437-3446. [PubMed: 19675898]

163. Ali S, Ahmad I, Peters A, Masters G, Minchey S, Janoff A, Mayhew E. Hydrolyzable hydrophobic taxanes: synthesis and anti-cancer activities. Anticancer Drugs. 2001; 12:117-128. [PubMed: 11261884]

164. Dhanikula AB, Panchagnula R. Preparation and characterization of water-soluble prodrug, liposomes and micelles of Paclitaxel. Curr Drug Deliv. 2005; 2:75-91. [PubMed: 16305410]

165. Zhigaltsev IV, Winters G, Srinivasulu M, Crawford J, Wong M, Amankwa L, Waterhouse D, Masin D, Webb M, Harasym N, Heller L, Bally MB, Ciufolini MA, Cullis PR, Maurer N. Development of a weak-base docetaxel derivative that can be loaded into lipid nanoparticles. Journal of Controlled Release. 2010; 144:332-340. [PubMed: 20202473]

166. Parness J, Kingston DG, Powell RG, Harracksingh C, Horwitz SB. Structure-activity study of cytotoxicity and microtubule assembly in vitro by taxol and related taxanes. Biochem Biophys Res Commun. 1982; 105:1082-1089. [PubMed: 6124250]

167. Zhu Q, Guo Z, Huang N, Wang M, Chu F. Comparative molecular field analysis of a series of paclitaxel analogues. J Med Chem. 1997; 40:4319-4328. [PubMed: 9435901]

168. Kingston DG. Recent advances in the chemistry of taxol. J Nat Prod. 2000; 63:726-734. [PubMed: 10843603]

169. Byrne JD, Betancourt T, Brannon-Peppas L. Active targeting schemes for nanoparticle systems in cancer therapeutics. Adv Drug Deliv Rev. 2008; 60:1615-1626. [PubMed: 18840489]

170. Low PS, Antony AC. Folate receptor-targeted drugs for cancer and inflammatory diseases. Adv Drug Deliv Rev. 2004; 56:1055-1058. [PubMed: 15094205]

171. Elnakat H, Ratnam M. Distribution, functionality and gene regulation of folate receptor isoforms: implications in targeted therapy. Adv Drug Deliv Rev. 2004; 56:1067-1084. [PubMed: 15094207]

172. Wu J, Liu Q, Lee RJ. A folate receptor-targeted liposomal formulation for paclitaxel. Int J Pharm. 2006; 316:148-153. [PubMed: 16564654]

173. Liu Y, Li K, Pan J, Liu B, Feng SS. Folic acid conjugated nanoparticles of mixed lipid monolayer shell and biodegradable polymer core for targeted delivery of Docetaxel. Biomaterials. 2010; 31:330-338. [PubMed: 19783040]

174. Xu Z, Chen L, Gu W, Gao Y, Lin L, Zhang Z, Xi Y, Li Y. The performance of docetaxel-loaded solid lipid nanoparticles targeted to hepatocellular carcinoma. Biomaterials. 2009; 30:226-232. [PubMed: 18851881]

175. Ritter CA, Arteaga CL. The epidermal growth factor receptor-tyrosine kinase: a promising therapeutic target in solid tumors. Semin Oncol. 2003; 30:3-11. [PubMed: 12644979]

176. Gao Y, Chen L, Gu W, Xi Y, Lin L, Li Y. Targeted nanoassembly loaded with docetaxel improves intracellular drug delivery and efficacy in murine breast cancer model. Mol Pharm. 2008; 5:1044-1054. [PubMed: 19434922]

177. Moody TW, Gozes I. Vasoactive intestinal peptide receptors: a molecular target in breast and lung cancer. Curr Pharm Des. 2007; 13:1099-1104. [PubMed: 17430173] 
178. Gespach C, Bawab W, de Cremoux P, Calvo F. Pharmacology, molecular identification and functional characteristics of vasoactive intestinal peptide receptors in human breast cancer cells. Cancer Res. 1988; 48:5079-5083. [PubMed: 2842044]

179. Rubinstein I, Soos I, Onyuksel H. Intracellular delivery of VIP-grafted sterically stabilized phospholipid mixed nanomicelles in human breast cancer cells. Chem Biol Interact. 2008; 171:190-194. [PubMed: 17499651]

180. Pirollo KF, Chang EH. Does a targeting ligand influence nanoparticle tumor localization or uptake? Trends Biotechnol. 2008; 26:552-558. [PubMed: 18722682]

181. Bartlett DW, Su H, Hildebrandt IJ, Weber WA, Davis ME. Impact of tumor-specific targeting on the biodistribution and efficacy of siRNA nanoparticles measured by multimodality in vivo imaging. Proc Natl Acad Sci U S A. 2007; 104:15549-15554. [PubMed: 17875985]

182. Kirpotin DB, Drummond DC, Shao Y, Shalaby MR, Hong K, Nielsen UB, Marks JD, Benz CC, Park JW. Antibody targeting of long-circulating lipidic nanoparticles does not increase tumor localization but does increase internalization in animal models. Cancer Res. 2006; 66:6732-6740. [PubMed: 16818648]

183. Wu AM, Yazaki PJ, Tsai S, Nguyen K, Anderson AL, McCarthy DW, Welch MJ, Shively JE, Williams LE, Raubitschek AA, Wong JY, Toyokuni T, Phelps ME, Gambhir SS. High-resolution microPET imaging of carcinoembryonic antigen-positive xenografts by using a copper-64labeled engineered antibody fragment. Proc Natl Acad Sci U S A. 2000; 97:8495-8500. [PubMed: 10880576]

184. Hussain S, Pluckthun A, Allen TM, Zangemeister-Wittke U. Antitumor activity of an epithelial cell adhesion molecule-targeted nanovesicular drug delivery system. Mol Cancer Ther. 2007; 6:3019-3027. [PubMed: 18025286]

185. Kircheis R, Wightman L, Schreiber A, Robitza B, Rossler V, Kursa M, Wagner E. Polyethylenimine/DNA complexes shielded by transferrin target gene expression to tumors after systemic application. Gene Ther. 2001; 8:28-40. [PubMed: 11402299]

186. Muller RH, Ruhl D, Runge S, SchulzeForster K, Mehnert W. Cytotoxicity of solid lipid nanoparticles as a function of the lipid matrix and the surfactant. Pharm Res. 1997; 14:458-462. [PubMed: 9144731]

187. Muller RH, Maassen S, Weyhers H, Specht F, Lucks JS. Cytotoxicity of magnetite-loaded polylactide, polylactide/glycolide particles and solid lipid nanoparticles. Int J Pharmaceut. 1996; 138:85-94.

188. Fu K, Pack DW, Klibanov AM, Langer R. Visual evidence of acidic environment within degrading poly(lactic-co-glycolic acid) (PLGA) microspheres. Pharm Res. 2000; 17:100-106. [PubMed: 10714616]

189. Majoros IJ, Myc A, Thomas T, Mehta CB, Baker JR Jr. PAMAM dendrimer-based multifunctional conjugate for cancer therapy: synthesis, characterization, and functionality. Biomacromolecules. 2006; 7:572-579. [PubMed: 16471932]

190. Lim J, Simanek EE. Synthesis of water-soluble dendrimers based on melamine bearing 16 paclitaxel groups. Org Lett. 2008; 10:201-204. [PubMed: 18088131]

191. Ooya T, Lee J, Park K. Hydrotropic dendrimers of generations 4 and 5: synthesis, characterization, and hydrotropic solubilization of paclitaxel. Bioconjug Chem. 2004; 15:12211229. [PubMed: 15546187]

192. Lacko AG, Nair M, Prokai L, McConathy WJ. Prospects and challenges of the development of lipoprotein-based formulations for anti-cancer drugs. Expert Opin Drug Deliv. 2007; 4:665-675. [PubMed: 17970668]

193. McConathy WJ, Nair MP, Paranjape S, Mooberry L, Lacko AG. Evaluation of synthetic/ reconstituted high-density lipoproteins as delivery vehicles for paclitaxel. Anticancer Drugs. 2008; 19:183-188. [PubMed: 18176115]

194. Masquelier M, Vitols S, Palsson M, Mars U, Larsson BS, Peterson CO. Low density lipoprotein as a carrier of cytostatics in cancer chemotherapy: Study of stability of drug-carrier complexes in blood. Journal of Drug Targeting. 2000; 8:155-164. [PubMed: 10938525]

195. Eisenberg S, Windmueller HG, Levy RI. Metabolic fate of rat and human lipoprotein apoproteins in the rat. J Lipid Res. 1973; 14:446-458. [PubMed: 4351783] 
196. Ho YK, Smith RG, Brown MS, Goldstein JL. Low-density lipoprotein (LDL) receptor activity in human acute myelogenous leukemia cells. Blood. 1978; 52:1099-1114. [PubMed: 214187]

197. Fiorenza AM, Branchi A, Sommariva D. Serum lipoprotein profile in patients with cancer. A comparison with non-cancer subjects. Int J Clin Lab Res. 2000; 30:141-145. [PubMed: 11196072]

198. Mooberry LK, Nair M, Paranjape S, McConathy WJ, Lacko AG. Receptor mediated uptake of paclitaxel from a synthetic high density lipoprotein nanocarrier. J Drug Target. 2010; 18:53-58. [PubMed: 19637935]

199. Yezhelyev M, Yacoub R, O’Regan R. Inorganic nanoparticles for predictive oncology of breast cancer. Nanomedicine (Lond). 2009; 4:83-103. [PubMed: 19093898]

200. Lu J, Liong M, Sherman S, Xia T, Kovochich M, Nel AE, Zink JI, Tamanoi F. Mesoporous Silica Nanoparticles for Cancer Therapy: Energy-Dependent Cellular Uptake and Delivery of Paclitaxel to Cancer Cells. Nanobiotechnology. 2007; 3:89-95. [PubMed: 19936038]

201. Paciotti GF, Kingston DGI, Tamarkin L. Colloidal gold nanoparticles: A novel nanoparticle platform for developing multifunctional tumor-targeted drug delivery vectors. Drug Develop Res. 2006; 67:47-54.

202. Hwu JR, Lin YS, Josephrajan T, Hsu MH, Cheng FY, Yeh CS, Su WC, Shieh DB. Targeted Paclitaxel by conjugation to iron oxide and gold nanoparticles. J Am Chem Soc. 2009; 131:6668. [PubMed: 19072111]

203. Hua MY, Yang HW, Chuang CK, Tsai RY, Chen WJ, Chuang KL, Chang YH, Chuang HC, Pang ST. Magnetic-nanoparticle-modified paclitaxel for targeted therapy for prostate cancer. Biomaterials. 2010; 31:7355-7363. [PubMed: 20609471]

204. Gibson JD, Khanal BP, Zubarev ER. Paclitaxel-functionalized gold nanoparticles. J Am Chem Soc. 2007; 129:11653-11661. [PubMed: 17718495]

205. van Schooneveld MM, Vucic E, Koole R, Zhou Y, Stocks J, Cormode DP, Tang CY, Gordon RE, Nicolay K, Meijerink A, Fayad ZA, Mulder WJ. Improved biocompatibility and pharmacokinetics of silica nanoparticles by means of a lipid coating: a multimodality investigation. Nano Lett. 2008; 8:2517-2525. [PubMed: 18624389] 

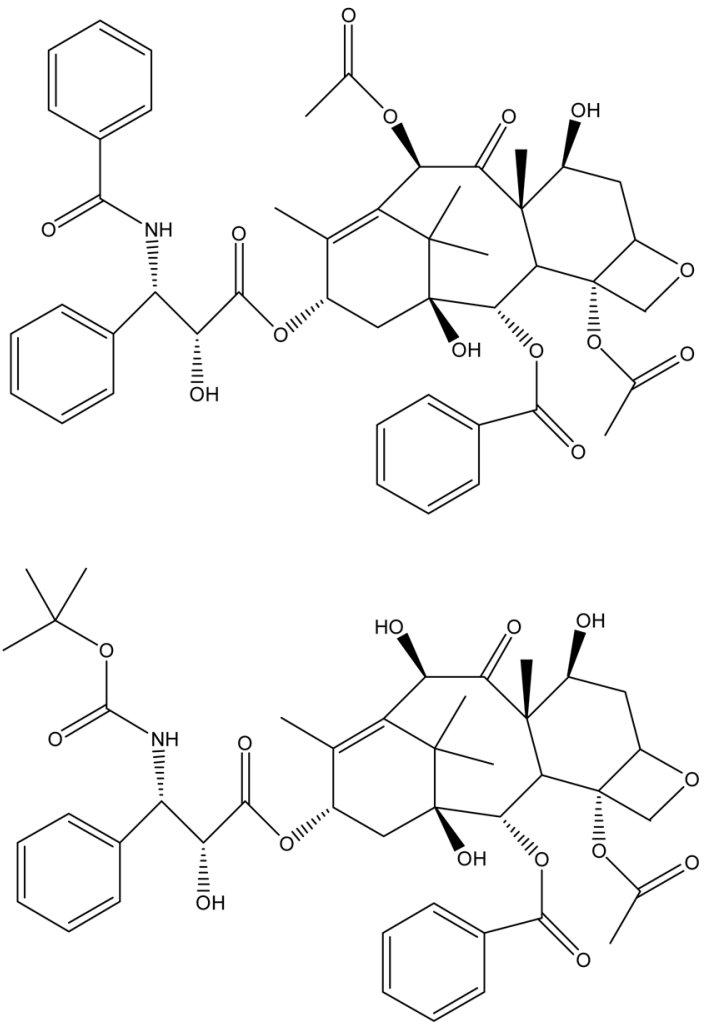

Figure 1.

Structures of (A) paclitaxel and (B) docetaxel 


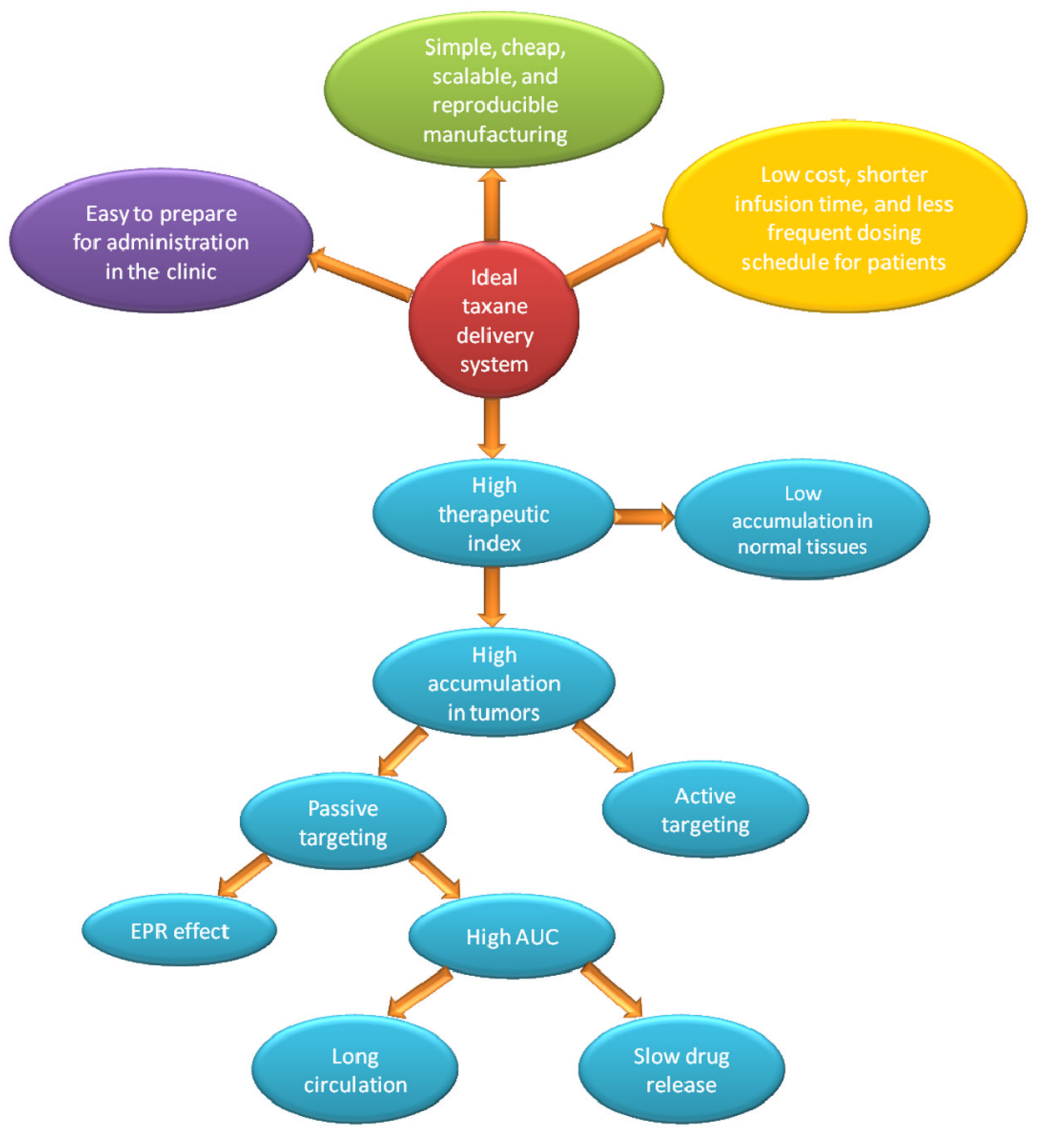

Figure 2.

Criteria for the ideal taxane delivery system 


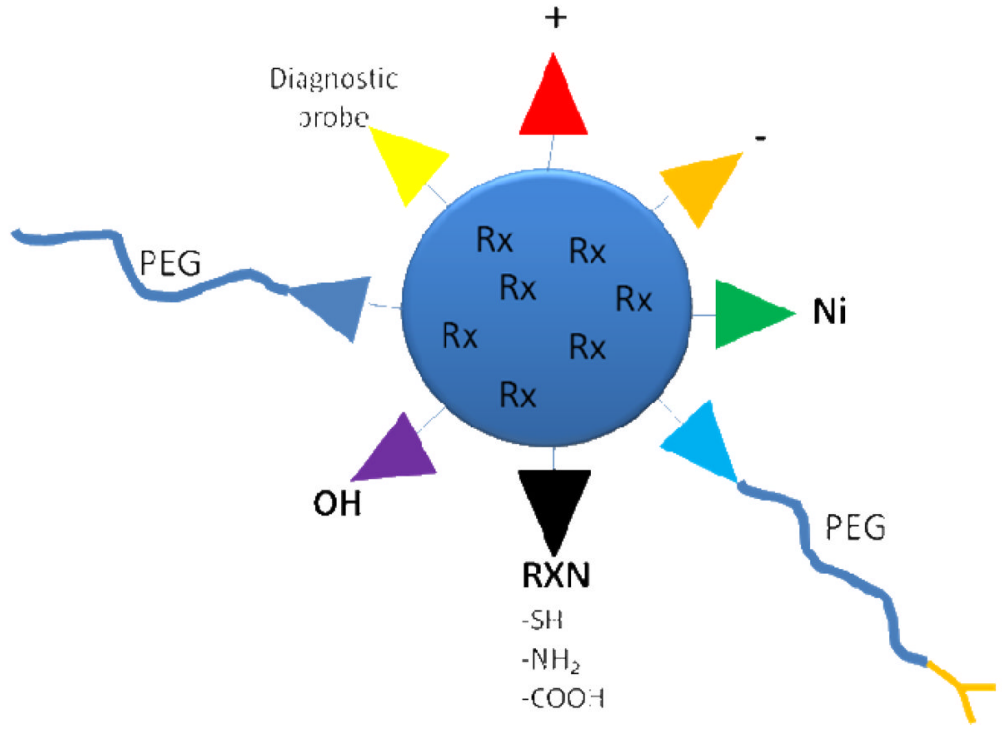

Figure 3.

Multi-functionality of lipid-based nanoparticles 


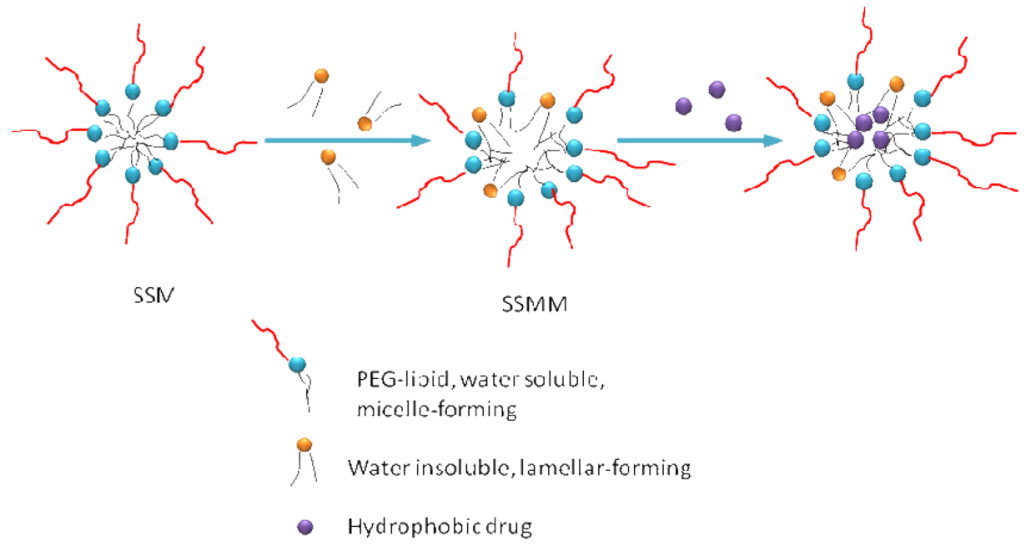

Figure 4.

Schematic structures of sterically stabilized micelle (SSM), sterically stabilized mixed micelle (SSMM) and SSMM loaded hydrophobic drug molecules 


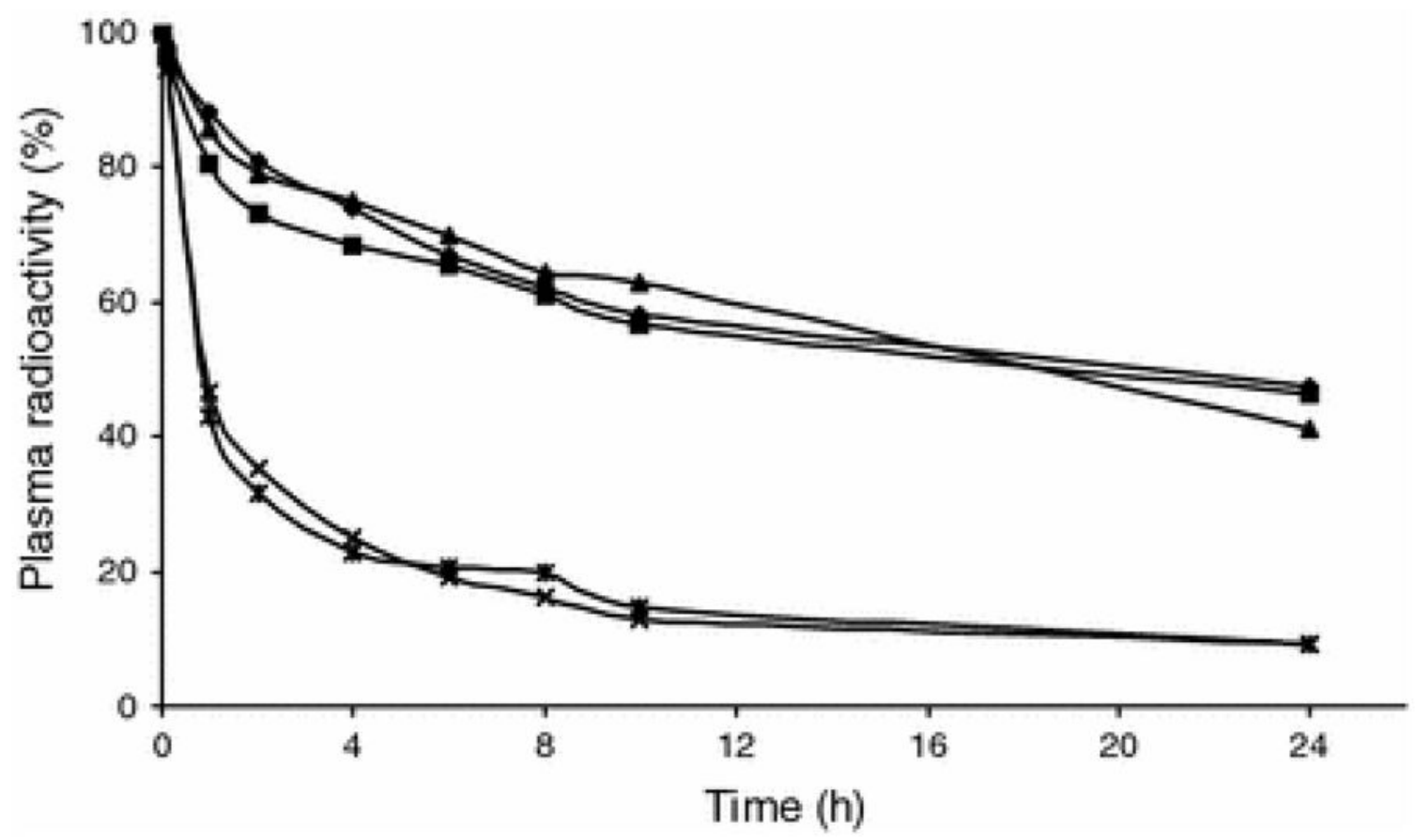

Figure 5.

Plasma decay curve of $\left[{ }^{3} \mathrm{H}\right]$-paclitaxel-oleate in LDL-resembling nano-emulsion (three patients, filled diamond, triangle and square) and $\left[{ }^{3} \mathrm{H}\right]$-paclitaxel in CrEL (two patients, multi symbol, asterisk) following i.v. bolus injection. Reprinted from Ref [118] with permission. 


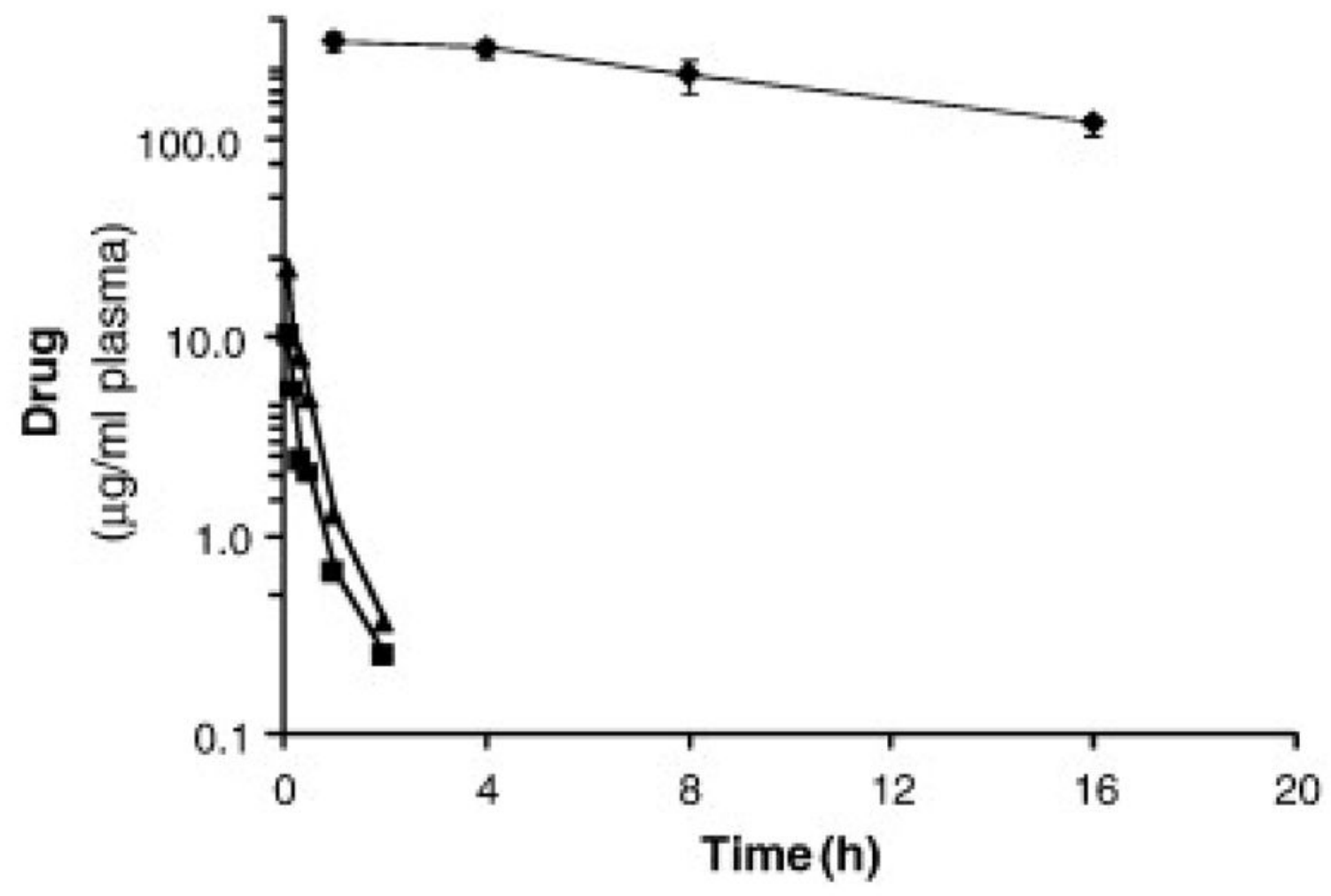

Figure 6.

Plasma concentration-time curves for Taxotere (triangle), docetaxel derivative formulated in Taxotere vehicle (square), and docetaxel derivative formulated in DSPC/Chol liposome (diamond). Reprinted from Ref [165] with permission. 


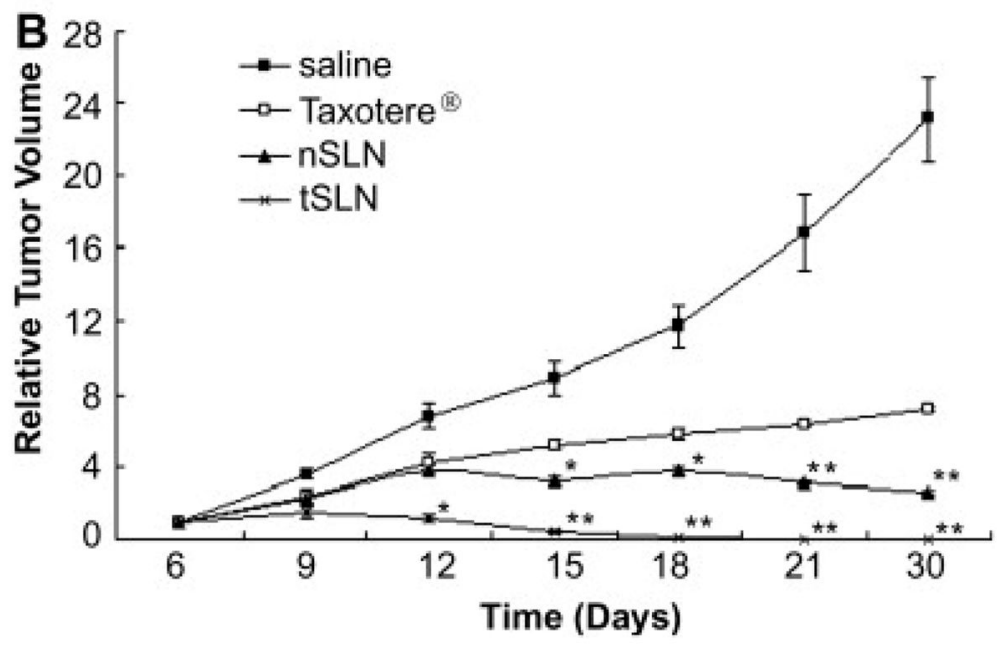

Figure 7.

Antitumor efficacy of targeted SLN (tSLN), non-targeted SLN (nSLN), Taxotere or saline on nude mice bearing hepatoma after a schedule of multiple doses (10 $\mathrm{mg}$ docetaxel $/ \mathrm{kg}$ once a week for three weeks). Data are presented as mean \pm SD $(n=5-6)$. Reprinted from Ref [174] with permission. 
Table 1

Similarities and differences between paclitaxel and docetaxel

\begin{tabular}{l|l}
\hline Similarity & Difference \\
\hline Structure taxane skeleton & Structure \\
& Paclitaxel, 10-acetyl group, $3^{\prime}$-benzamide phenyl group \\
& Docetaxel, 10-OH, $3^{\prime}-\mathrm{OC}\left(\mathrm{CH}_{3}\right)_{3}$ \\
Pharmacological mechanism & Water solubility \\
Inhibition of microtubule depolymerization & Paclitaxel, 0.35-0.7 $\mu \mathrm{g} / \mathrm{mL}$ \\
& Docetaxel, 3-25 $\mu \mathrm{g} / \mathrm{mL}$ \\
& Uptake and efflux \\
& Docetaxel 3-fold higher uptake and 3-fold slower efflux than paclitaxel \\
& Microtubule binding affinity \\
& Docetaxel 1.9-fold higher than paclitaxel \\
& Anticancer potency \\
& Docetaxel about twice as potent as paclitaxel in-vitro and in-vivo \\
& Pharmacokinetics \\
& Paclitaxel, nonlinear \\
& Docetaxel, linear up to $115 \mathrm{mg} / \mathrm{m}^{2}$ \\
\hline
\end{tabular}


Table 2

Similarities and differences between nano-emulsions and micro-emulsions

\begin{tabular}{c|l|l}
\hline & \multicolumn{2}{|c}{ Similarity } \\
\hline Appearance & Transparent or translucent \\
\hline Size & In the nano-scale range \\
\hline Structure & Spherical nano-scaled droplets dispersed in a continuous phase \\
\cline { 2 - 3 } & \multicolumn{2}{|c}{ Difference } \\
\hline \multirow{2}{*}{ Stability } & \multicolumn{1}{|c}{ Nano-emulsion } & \multicolumn{1}{|c}{ Minetically stable } \\
\hline \multirow{2}{*}{ Preparation } & $\begin{array}{l}\text { Energy is required } \\
\text { High-energy methods: high-pressure } \\
\text { homogenization, ultrasonification } \\
\text { low-energy methods: } \text { PIT method, } \\
\text { "spontaneous" emulsification }\end{array}$ & $\begin{array}{l}\text { Thergy is not required } \\
\text { Spontaneously formed in the micro-emulsion forming domain } \\
\text { accelerate the equilibrium }\end{array}$ \\
\hline Destabilization mechanism & Oswald ripening & Dilution and temperature \\
\hline Application & Parenteral drug delivery among others & Oral and topical delivery, not suitable for parenteral delivery \\
\hline
\end{tabular}


Table 3

Major advantages and disadvantages of each type of lipid-based nanoparticles

\begin{tabular}{c|l|l}
\hline & Advantages & Disadvantages \\
\hline Liposomes & $\begin{array}{l}\text { Mature production engineering and scale-up techniques, } \\
\text { capable of encapsulate both lipophilic and hydrophilic } \\
\text { molecules }\end{array}$ & $\begin{array}{l}\text { Drug leakage, low loading capacity to lipophilic } \\
\text { drugs }\end{array}$ \\
\hline Micelles & Easy production & $\begin{array}{l}\text { Relatively low drug loading capacity, potential } \\
\text { dissociation upon dilution }\end{array}$ \\
\hline Nano-emulsions & High drug loading capacity, versatile chemistry & Relatively low stability and drug retention \\
\hline Solid lipid nanoparticles & $\begin{array}{l}\text { Ease of preparation and scale-up with low cost, good } \\
\text { physical stability, controlled drug release, versatile } \\
\text { chemistry }\end{array}$ & Potential of drug expulsion and burst release \\
\hline Nanocapsules & $\begin{array}{l}\text { High drug loading capacity, good drug retention, high } \\
\text { stability }\end{array}$ & $\begin{array}{l}\text { Low entrapment efficiency of polymer-shelled } \\
\text { nanocapsules }\end{array}$ \\
\hline
\end{tabular}


Table 4

Advantages and disadvantages of lipid-based nanoparticles compared to other nano-based delivery systems

\begin{tabular}{l|l|l}
\hline & Advantages & Disadvantages \\
\hline Lipid-based nanoparticles & High biocompatibility & Low CMC of lipid micelles \\
\hline Polymeric nanoparticles & $\begin{array}{l}\text { More versatile chemistry and more functionality, More } \\
\text { stable active ligand incorporation }\end{array}$ & $\begin{array}{l}\text { Higher toxicity, organic solvent involvement } \\
\text { during preparation, scale-up difficulty }\end{array}$ \\
\hline Natural macromolecules & $\begin{array}{l}\text { High biocompatibility, functional capacity to deliver } \\
\text { hydrophobic drugs, intrinsic targeting property }\end{array}$ & Production difficulty, high cost \\
\hline Inorganic nanoparticles & Simultaneous optical imaging & Low biocompatibility \\
\hline
\end{tabular}

